Article

\title{
Implementation and Simulation of Real Load Shifting Scenarios Based on a Flexibility Price Market Strategy-The Italian Residential Sector as a Case Study
}

\author{
Francesco Mancini ${ }^{1, * \mathbb{C}}$, Jacopo Cimaglia ${ }^{2}$, Gianluigi Lo Basso ${ }^{3}\left[\right.$ and Sabrina Romano ${ }^{4}$ \\ 1 Department of Planning, Design and Technology of Architecture, Sapienza University of Rome, \\ 72-00197 Rome, Italy \\ 2 Interdepartmental Center for Territory, Building, Conservation and Environment, \\ Sapienza University of Rome, 53-00197 Rome, Italy; jacopocimaglia.ingegneria@gmail.com \\ 3 Department of Astronautics, Electrical Energy Engineering, Sapienza University of Rome, \\ 18-00184 Rome, Italy; gianluigi.lobasso@uniroma1.it \\ 4 Energy Technologies Department (DTE), Italian National Agency for Technologies, \\ Energy and Sustainable Economic Development (ENEA), 301-00123 Rome, Italy; sabrina.romano@enea.it \\ * Correspondence: francesco.mancini@uniroma1.it; Tel.: +39-06-4991-9172
}

Citation: Mancini, F.; Cimaglia, J.; Lo Basso, G.; Romano, S.

Implementation and Simulation of Real Load Shifting Scenarios Based on a Flexibility Price Market

Strategy-The Italian Residential Sector as a Case Study. Energies 2021, 14, 3080. https://doi.org/10.3390/ en14113080

Academic Editors:

Mahdi Pourakbari-Kasmaei and Seppo Sierla

Received: 4 May 2021

Accepted: 21 May 2021

Published: 25 May 2021

Publisher's Note: MDPI stays neutral with regard to jurisdictional claims in published maps and institutional affiliations.

Copyright: (c) 2021 by the authors. Licensee MDPI, Basel, Switzerland. This article is an open access article distributed under the terms and conditions of the Creative Commons Attribution (CC BY) license (https:/ / creativecommons.org/licenses/by/ $4.0 /)$.

\begin{abstract}
This work aims to evaluate the Flexibility Potential that a residential household can effectively provide to the public grid for participating in a Demand Response activity. In detail, by using 14 dwellings electrical data collection, an algorithm to simulate the Load Shifting activity over the daytime is implemented. That algorithm is applied to different scenarios having considered the addition of several technical constraints on the end users' devices. In such a way, more realistic demand-side management actions are implemented in order to assess the Flexibility Potential deriving from the loads shifting. Basically, by performing simulations it is possible to investigate how the household appliances real operating conditions can reduce the theoretical Flexibility Potential extent. Starting from a Flexibility Price-Market-based Strategy, this work simulates the shifting over the day and night-time of some flexible loads, i.e., the shiftable and the storable ones. Specifically, all instants where load curtailments and enhancements occur over the typical day, the flexibility strategy effectiveness in terms of percentage, the power and energy that are potentially flexible, are evaluated. All the simulations are performed only for residential consumers to evaluate the actual dwellings Flexibility Potential in the absence of any electrical storage and production systems. The outcomes of these simulations show an average Theoretical Flexibility reduction, which is calculated as the fraction of appliances' cycles shifting over the total ones, equal to $53 \%$, instead of $66 \%$; in a single dwelling, a maximum variation equal to $29 \%$ has been registered. In the end, the monthly average shifted energy per dwellings decreases from 27 to $18 \mathrm{kWh}$, entailing $32.5 \%$ off.
\end{abstract}

Keywords: residential users; demand response; flexible loads shifting scenarios

\section{Introduction}

The European Union long-term strategic vision concerns a detailed analysis of all those actions to be undertaken for a greenhouse gasses zero emissions economy within 2050 . The outlined scenarios provide the use of Renewable Energy Sources (RES) on large-scale [1]. However, a large quantity of electricity produced by non-programmable RES, may cause electrical grid management problems, due to potential mismatch between energy supply and energy demand [2].

An efficient balancing method is represented by the Demand-Side Management activities (DSM), which have the goal of encouraging consumers to modify their electrical energy use, either reducing their consumptions or shifting the power uptakes towards off-peak hours; in detail, among the DSM activities, a great interest was addressed to the Demand Response (DR) [3], which aims at reshaping the users' power demand profiles according to 
the grid requirements. DR helps public service enterprises and users to reduce peak power demand and the energy prices variability [4], converting the users into load management market active participants [5].

From a literature overview, it emerged how the DSM strategies implementation was adopted very often to improve energy and economic savings in big industrial sites; Notwithstanding, in the recent years, an increasing attention to the potential role of residential sector in the flexibility market has been paid. Even though costly ICT infrastructures to send signals from or towards the individual house are required, several research activities were focused on developing less expensive components and sensors to make them accessible and handy in the medium short term. Additionally, potential incentive schemes have been proposed in order to improve the end-users' profitability and to contribute to a wider deployment.

The growing interest in the implementation of DR programs to dwellings is basically due to the high energy needs in the building sector; indeed, in the EU member states, the real estate energy needs accounted for $40.3 \%$ of total consumption; namely, the building stock alone accounted for $26.1 \%$ of total energy consumptions, in accordance with data referred to 2018 [6]. It is noteworthy that a part of residential consumption is electrical, and only a fraction of can be considered appropriate to be used flexibly. Having said this, a great potentiality is represented by all those buildings equipped with electric heat generators; the positive effect magnitude on overall consumption is strongly related to the climatic zone (i.e., outdoor temperature and relative humidity), to the buildings' envelope as well as to the occupancy rate [7].

Several research projects addressed the issue associated to the identification of the most proper methodology to assess the buildings' potential of flexibility [8]. For instance, the authors in Ref. [9] proposed a predictive model to accurately schedule both the users and the energy resources which can be deferred over the day. The buildings' thermal mass can be reputed as a potential storage medium $[10,11]$. Indeed, that mass, which is a specific feature of each dwelling, it can store a certain amount of heat by either postponing or anticipating the operating time schedule of heating and cooling systems. In such a way, the indoor thermal comfort conditions can be kept under control to the standard set point [12]. Among the different available options to handle the load flexibility, the so-called Power-to-X strategies are currently offering good perspectives. Usually, the $X$ letter is used as an umbrella terms to indicate the electricity conversion, hailing from the renewables' overcapacity, into different useful energy forms. Referring to the building sector, Power-to-Power, Power-to-Heat and Power-to-Gas are considered, by the scientific community, as the most promising and suitable options in the short-medium term [13-16]. However, cheaper and reliable storage devices, such as PCMs (Phase-change Materials), pressurized gas vessels, batteries and the electro-fuels injection into NG pipelines, have to be effectively embedded within the existing energy scenarios [17]. On the other hand, the recent literature, dealing with how to conveniently store heat in the residential sector, is strongly oriented to analyse the widespread electric heat pumps application for serving the end users in terms of Domestic Hot Water production (DHW as well [18]).

In accordance with the mentioned research indications, and based on what has emerged when applying the management strategy proposed in a previous work [19], different scenarios have been built. Specifically, they also include several constraints, in order to evaluate their effects on the dwellings' flexible potential. The study is based on a measurement campaign carried out over two years (2018-2019) related to 14 sample dwellings representing the middle regions Italian building stock; that cluster was chosen by selecting the most frequent typologies within a database consisting of 751 real dwellings. The database was built over the last three years by collecting a wide group of information, such as geometrical characteristics, building materials and energy bills.

Having said this, the authors deem that their contribution to the knowledge in this research topic is substantially the methodological approach, which integrates on-field measurements with a simulation process; more specifically, the authors attempt to identify 
how the DSM strategies effectiveness drift away from theoretical values once realistic technical constraints on devices operation have been considered in calculation model. By combining several tools for statistical analysis, the dwellings' electrical loads have been analysed, classified, filtered, and then processed to verify the realistic flexibility. Moreover, this study aims at contributing to identify the potential role of Italian residential sector within the long-term strategy of progressively transforming the end users' energy consumptions. Indeed, a high electrification degree is well recognised as one of the most important drivers in the energy transition, towards an efficient RES integration within the national grid.

\section{Materials and Methods}

An effective DR program implementation generally needs an accurate knowledge of what a generic dwelling can offer, in terms of shiftable loads, for participating in such a strategy. Considering a single household, the flexibility potential is low and discontinuous very often; nevertheless, by gathering several dwellings it is possible to mitigate such discontinuities and to flatten the flexible loads amount over specific time spans. In so doing, building clusters or districts can fruitfully contribute to the electrical systems management along with improving their own safety and reliability issues [20].

The loads classification based on their intrinsic nature [21] can be useful only for preliminary analysis (see Figure 1), providing to designers with a flexibility amount overestimation: (i) all those loads deemed as flexible in accordance with the classification might be not-flexible related to the specific management strategy [22,23]; (ii) other loads might be not-flexible caused by different technical constraints related to the household appliances [24]. Those ones, can be eventually imposed by a building energy management system (e.g., BEMS) [25]. This latter, including several probes, sensors, transducers and interfaces, is characterised by a purchase price ranging between 1000 and $4000 €$ as the household size increases together with technical requirements, specifications and remote controls [26].

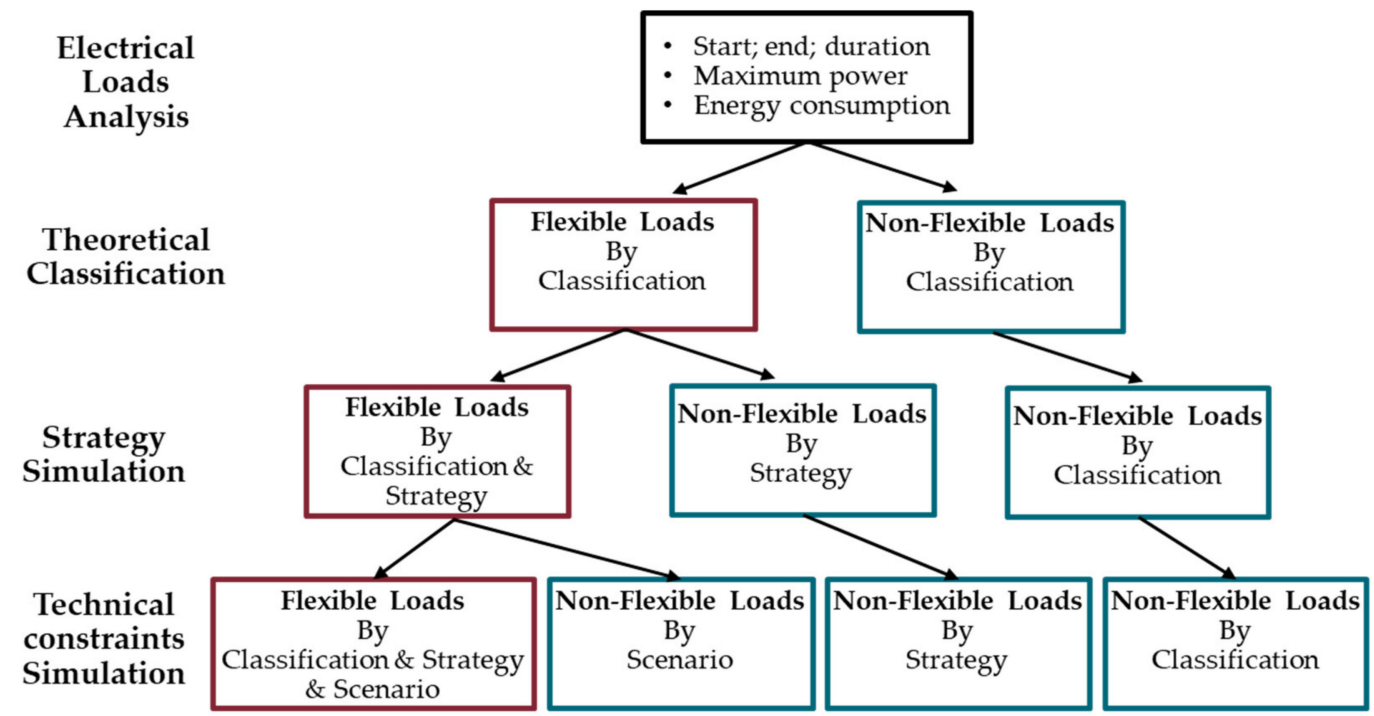

Figure 1. Flexible Loads quantification process.

In this work, the management strategy developed in a previous project of the same authors [19], are considered; this strategy was defined comparing the power demand profiles of a buildings cluster with the Italian hourly electricity price. In so doing, all those moments over the day, in which clusters should reduce or enhance their electrical uptakes, were detected. Consequently, optimized and reshaped power demand profiles, sorted by months and days typology, were built (i.e., weekdays, Saturdays, non-working days), as reported in Tables A1-A3 of Appendix A. 
Seven technical constraints have been identified (see Table 1) and they can be outlined as follows: (C1) is a maximum flexibility window of $24 \mathrm{~h}$ [27]; (C2) is the maximum withdrawable power from the grid as a function of delivery contracts related to the end user typology; (C3) the dwelling occupancy for some appliances operation (vacuum cleaner, iron, etc.) [28]; $(\mathrm{C} 4, \mathrm{C} 5)$ account for the working sequence of different appliances (washing machine, tumble dryer, dishwasher); (C6) takes into account the correlation between the users stochastic behaviour and the heating and cooling systems operation [29]; (C7) refers to different user settings imposed to avoid the satisfaction level lessening (of users themself and neighbours), e.g., for night-time noises.

Table 1. Operative bonds to the appliances working.

\begin{tabular}{ccc}
\hline Constraints (C) & Criterium & Definition \\
\hline C1 & Flexibility window & Maximum shifting within 24 h ahead \\
C2 & $\begin{array}{c}\text { Maximum power at the meter } \\
\text { (detachment conditions) }\end{array}$ & $\begin{array}{c}\mathrm{P}>14.0 \mathrm{~kW} \text { for } \tau>2 \mathrm{~s} \\
\mathrm{P}>4.2 \mathrm{~kW} \text { for } \tau>2 \mathrm{~min} \\
\mathrm{P}>3.3 \mathrm{~kW} \text { for } \tau>182 \mathrm{~min}\end{array}$ \\
\hline C3 & Vacuum cleaner and Iron using & Occupancy in dwelling \\
\hline C4 5 & Tumble Dryer and Washing Machine & TD operation within $3 \mathrm{~h}$ from WM cycle end \\
\hline C6 & Dish Washer & End of operation within next meal \\
\hline C7 & Heating and Cooling & $\begin{array}{c}\text { Occupancy within the next } 4 \mathrm{~h} \\
\text { (i.e., switching on within the previous } 4 \mathrm{~h} \\
\text { from the original starting) }\end{array}$ \\
\hline
\end{tabular}

Starting from the theoretical classification (S0), four scenarios were simulated with the aim of quantifying the flexible loads in the dwellings. Each scenario is characterised by the application of the aforementioned management strategy, along with the different constraints set and by the different impositions of the bond conditions set out above (see Table 2). The simulations were implemented using the Excel environment, with Macros written in Visual Basic for Applications (VBA).

Table 2. Simulated scenarios.

\begin{tabular}{cc}
\hline Scenario (S) & Criterium \\
\hline S0 & Theoretical Classification \\
\hline S1 2 & $\begin{array}{c}\text { Load Shifting Strategy Simulation; } \\
\text { No constraint Applied }\end{array}$ \\
\hline S3 & $\begin{array}{c}\text { Load Shifting Strategy Simulation; } \\
\text { constraints V1, V2, V3 Applied }\end{array}$ \\
\hline S4 & $\begin{array}{c}\text { Load Shifting Strategy Simulation; } \\
\text { constraints V1, V2, V3, V4, V5, V6 Applied }\end{array}$ \\
\hline Load Shifting Strategy Simulation; \\
constraints V1, V2, V3, V4, V5, V6, V7 Applied
\end{tabular}

The theoretical classification (S0) is based on a preliminary analysis carried out on the sample dwellings. It allows to estimate the flexibility in a "steady" way, once all of the flexible appliance cycles have been considered shiftable only by their nature; that implicitly means families are totally willing to participate in a DR program [21].

As regards the management strategy (S1) application, general flexible cycle hourly allocations and load shifting requests (i.e., "Load Reduction Time"; "Load Increase Time") were analysed and correlated, according to what is reported in Appendix A, Tables A1-A3); 
as a result, some loads have been considered not-flexible. In detail, loads belonging to that category are all those off-takes occurring at the right hourly allocation (cycle load in "Load Increase Time" o "No Load Variation"), together with the non-shiftable ones due to the lack of "Load Increase Time" subsequent requests.

The addition of further constraints, such as S2, S3 and S4, limits load amount to be shifted, owing to the incompatibility between some hourly allocation "Load Increase Time" and scenario's constraints.

The flexible loads were characterised by considering, for each working cycle of any appliances, the following parameters: (i) the starting time, (ii) the cycle duration; (iii) the consumed energy $\left(E_{\text {Flex }}\right)$; (iv) the maximum power $\left(P_{\max }\right)$.

The strategy and constraints application effects were evaluated by several indicators able to describe and summarize the flexibility amount in terms of statistical and energy values:

- Real Flexibility $(R F)$ is the effective fraction of the executed load shifting, respect to the appliance total cycles tally (see Equation (1));

- Energy Shift (ES) is the shifted energy consumption deriving from the adopted actions (see Equation (2));

- Peak Shaving (PS) is the maximum achievable peak reduction by the load shifting, in terms of power, between the scenario Sx and the theoretical one without shifting (S0) (see Equation (3)).

$$
\begin{gathered}
R F_{\mathrm{Sx}}=\frac{N_{\text {Flex }, \mathrm{Sx}}}{N_{\text {flex }, \mathrm{S} 0}} . \\
E S_{\mathrm{Sx}}=\sum E_{\text {Flex }, \mathrm{Sx}} \\
P S_{\mathrm{Sx}}=\operatorname{Max}\left(P_{\text {max }, \mathrm{S} 0}-P_{\text {max }, \mathrm{Sx}}\right)
\end{gathered}
$$

where:

- $\quad N_{\text {Flex,S0 }}$ is the total tally of flexible cycles before applying both strategy and constraints (i.e., it corresponds to scenario S0);

- $\quad N_{\text {Flex,Sx }}$ represents the number of effective executed load shifting, due to the scenario Sx application;

- $\quad P_{\max , \mathrm{S} 0}$. indicates the maximum registered power (in the time span of $15 \mathrm{~min}$ ) before applying the strategy and constraints (i.e., scenario S0);

- $\quad P_{\max , \mathrm{Sx}}$ represents the maximum registered power (in the time span of $15 \mathrm{~min}$ ), hailing from scenario Sx application, at the same time in which the $P_{\max , \mathrm{S} 0}$ value occurs.

The first indicator (RF) was expressly defined for the present analysis; the remaining two (ES, PS) were widely used in literature to evaluate the flexibility in the residential sector and to define the political implications of different scenarios in the energy markets [30]. They were also combined with the cost reduction assessment [31] and they were included for defining power storage management strategies [32].

The explained procedure was applied to 14 sample dwellings of 751, selected by the use of a categorizing algorithm [19]. Therefore, they are considered as archetypes representing part of the Italian residential sector and their main features are outlined in Appendix B. In such dwellings, some sensors were installed to monitor the electrical consumption (Appendix B, Table A4) and a measurement campaign was carried out over 2018-2019.

The methodology application has been preceded by data elaboration process of the acquired measurement. Indeed, the sensors sampling time and data collection is about $5 \mathrm{~s}$. The post-processing phase was performed in order to calculate average values over 15 min, according to the common Distributor's energy meters: Thus, all of calculations and analyses were carried out with these average values. 


\section{Results and Discussions}

\subsection{Flexible Loads by Classification}

Using a data collection questionnaire [21], the required information for simulating dwellings energy consumptions and for classifying loads were obtained. Specifically, collected data refer to the physical and geometrical dwelling characteristics, to plant equipment, to building occupancy, to household appliances typology and to their utilization (Appendix B, Tables A5 and A6). However, the selected archetypes show a modest electrification degree, equal to $36.8 \%$; furthermore, all of samples have a NG-based heating system; only one dwelling shows a DHW production by heat pump system; in 9 dwellings cooling system are installed for the air conditioning of some rooms ( 2 units per dwelling on average). All the dwellings are equipped with washing machine; a dishwasher is installed only in 11 dwellings, while the tumble dryer only in 4 dwellings; there are also some not-flexible appliances, such as ICTs, personal care items, refrigerators, ovens and kitchen appliances and others with a marginal usage. Among those, the vacuum cleaner and the iron are available in all dwellings and in 11 of them, respectively.

In the selected archetypes live different family typologies, in terms of composition, to adequately represent the Italian residential sector. The distribution can be summarised as follows: 3 households composed by 2 kids, a working parent and a non-working one; 2 households composed by 2 kids and 2 working parents; 4 households composed by 1 kid and 2 working parents; 2 households composed by 2 workers; one household composed by a single worker; 2 households composed by 2 non-workers.

Based on the data collection, some preliminary analyses were performed in order to identify the appliance cycles main features and the household's habits. In detail, a trend for the most energy-intensive appliances, characterised by the longest operation times, was detected: (i) the dishwasher shows an average starting operation time, in all cases and over the all months, occurring at 5:30 p.m. with an average variance of $+4: 30 \mathrm{~h}$ (40th percentile) and $-1: 30 \mathrm{~h}$ (60th percentile); (ii) the washing machine is commonly switched on close to 2:15 p.m. with an average variance of $+1: 30 \mathrm{~h}$ (40th percentile) and $-1: 45 \mathrm{~h}$ (60th percentile); the air conditioner usage is very diversified between the dwellings (different duration cycles, different temperature set-points) with an average starting operation time around 5:15 p.m. and an average variance of \pm 4:15 h. The remaining appliances show a higher variability and a lower cyclic nature. Therefore, it is not easy to identify a unique trend, exception for a large frequent time span occurring between 11:00 a.m. and 5:00 p.m. Anyway, it is clear how the users' working habits strongly affect appliance usage. Indeed, the electrical loads are mostly concentrated between 5:00 p.m. and 10:00 p.m., since the variance from the average value is greatly shifted towards the early evening hours. For instance, air conditioners and other minor appliances are dependent on the house occupancy; dishwashers must clean up dishes for dinner; washing machines and tumble dryers, if any, typically operate in the evening. Consequently, the power demand profiles related to the archetypes show peak values close to these hours, consistently with the national power demand profile [19].

The annual average daily profile of flexible loads related to the archetypes are depicted in Figures 2-4. It can be noticed how those loads are generally concentrated in the afternoon, exception for the weekdays (see Figure 2), where they are available early in the morning or after dinner. 


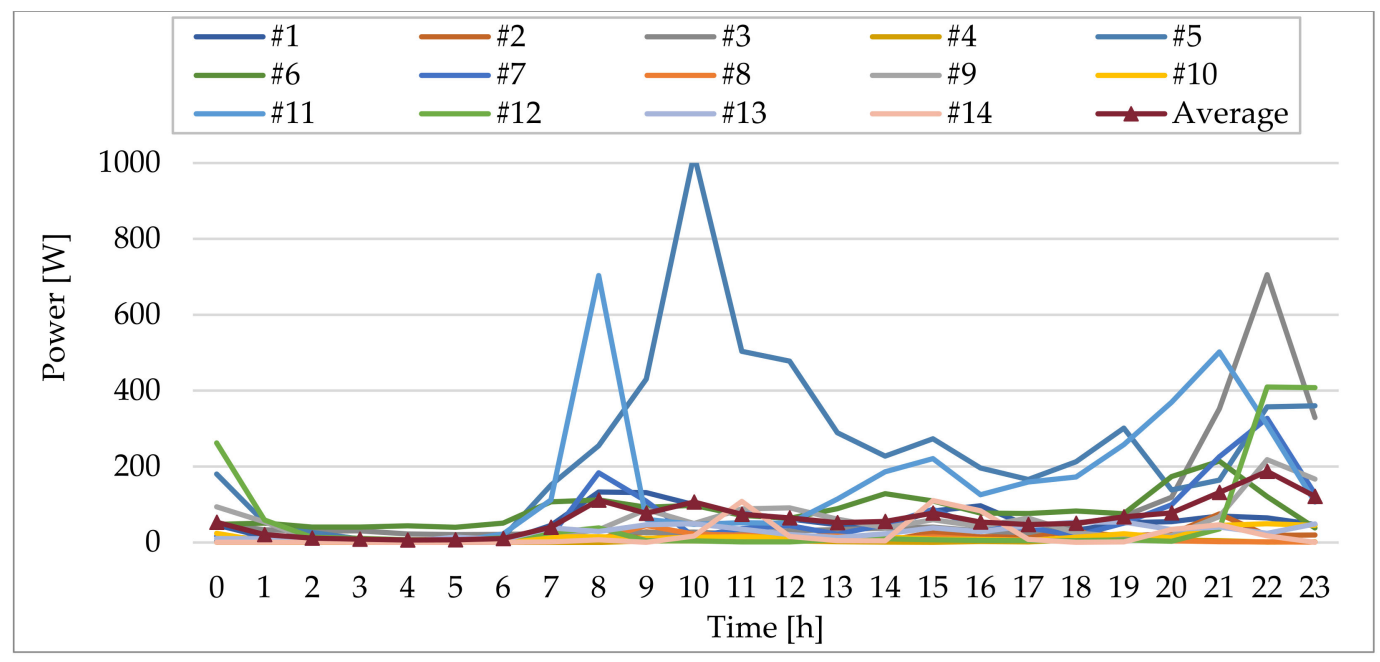

Figure 2. Archetypes average daily flexible loads profiles over the weekdays.

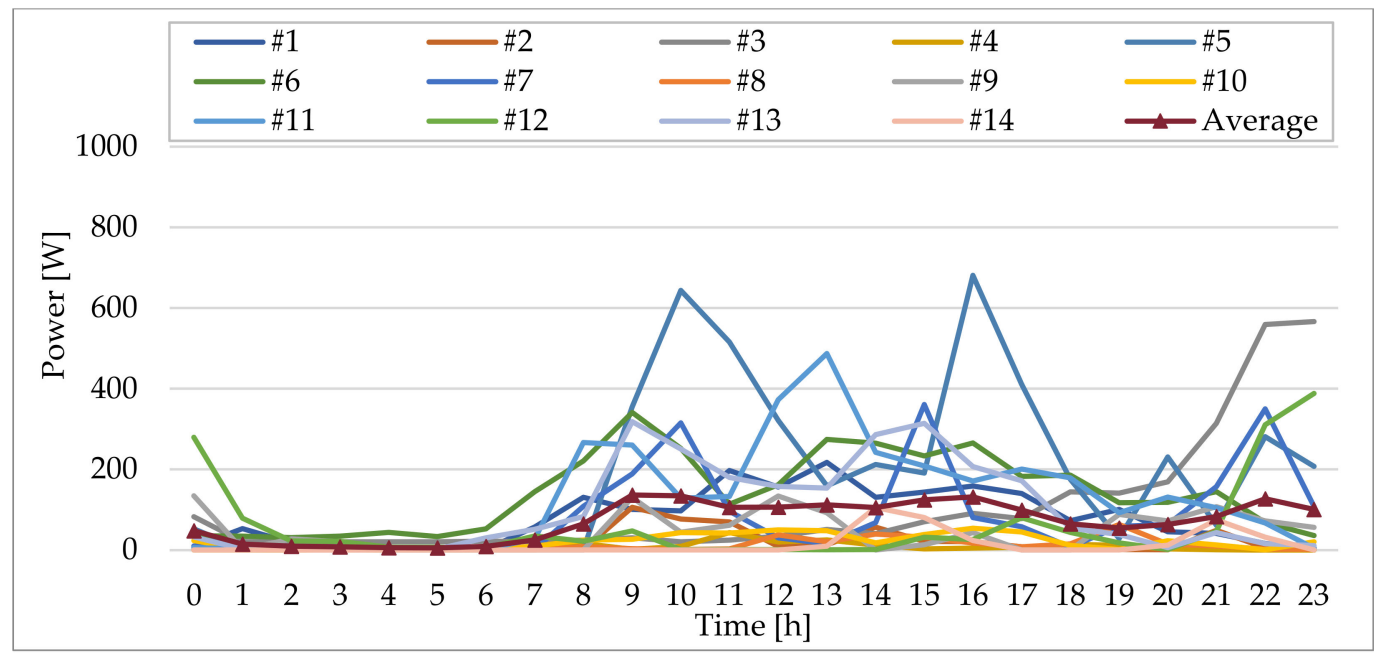

Figure 3. Archetypes average daily flexible loads profiles over the Saturdays.

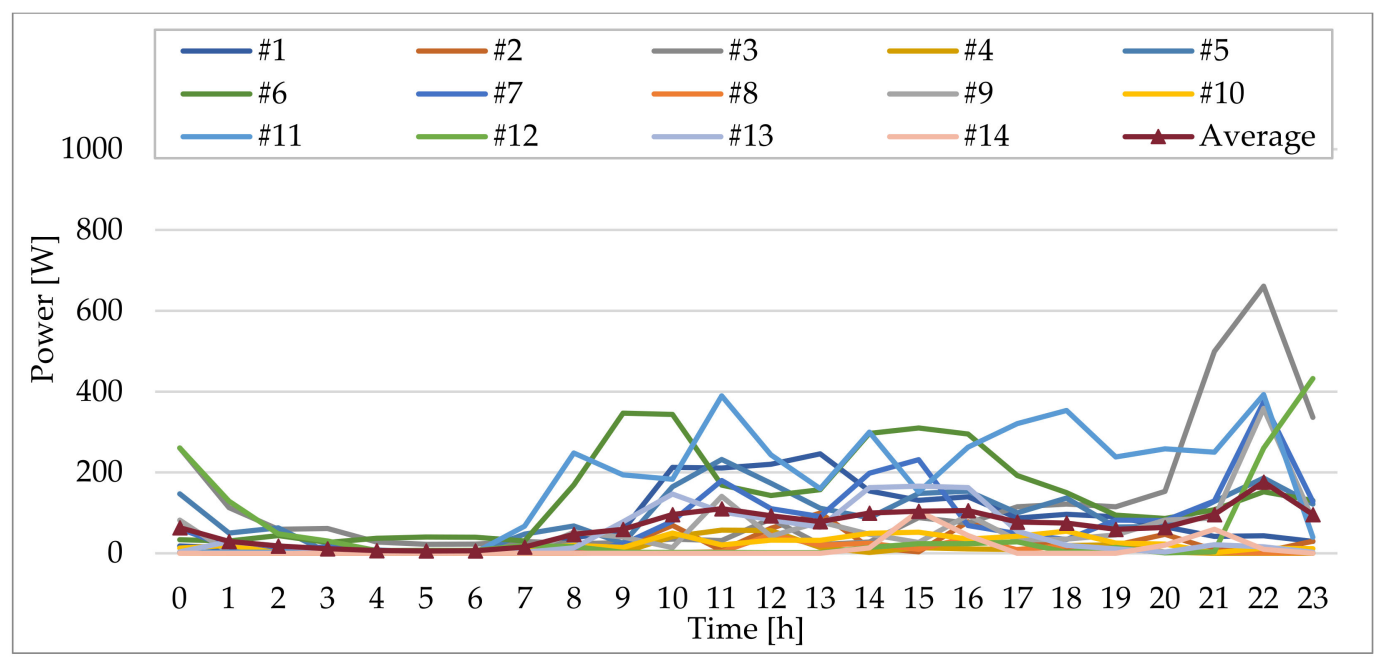

Figure 4. Archetypes average daily flexible loads profiles over non-working days. 
Referring to plotted data in Figures 3 and 4, it emerges how each archetype is characterised by different values of flexible power associated to the appliances' cycles. Even though a great variability occurs, a common trend in the usage has been found early in the morning, at lunchtime and after dinner.

Based on collected data, Table 3 shows the archetypes energy characterisation as a result of the applied methodology. Such a characterisation has been used to preliminary estimate the flexible loads extent, according to scenario S0. The averaged values of Flexible Loads and Non-Flexible Loads are equal to $811 \mathrm{kWh} / \mathrm{y}$ and $1333 \mathrm{kWh} / \mathrm{y}$, respectively.

Table 3. Archetypes reference parameters.

\begin{tabular}{|c|c|c|c|c|c|c|c|c|c|c|c|c|c|c|}
\hline \multirow{2}{*}{ Parameters } & \multicolumn{14}{|c|}{ Archetype } \\
\hline & $\# 1$ & $\# 2$ & $\# 3$ & $\# 4$ & $\# 5$ & $\# 6$ & \#7 & \#8 & $\# 9$ & $\# 10$ & $\# 11$ & $\# 12$ & $\# 13$ & \#14 \\
\hline$N_{\text {Flex }, \mathrm{S} 0}$ & 840 & 379 & 1030 & 172 & 1365 & 1261 & 1019 & 246 & 633 & 289 & 1868 & 650 & 984 & 504 \\
\hline $\begin{array}{c}\text { Flexible Loads } \\
\left(N_{\text {Flex }, \mathrm{S} 0}\right)[\mathrm{kWh} / \mathrm{y}]\end{array}$ & 858 & 294 & 660 & 355 & 1758 & 927 & 661 & 188 & 1096 & 728 & 866 & 1366 & 957 & 637 \\
\hline $\begin{array}{c}\text { Non-Flexible } \\
\text { Loads }[\mathrm{kWh} / \mathrm{y}]\end{array}$ & 2648 & 1024 & 1085 & 879 & 1298 & 1000 & 1099 & 881 & 2384 & 1218 & 1049 & 1754 & 1439 & 959 \\
\hline
\end{tabular}

\subsection{Flexible Loads by Strategy \& Scenario: Real Flexibility}

The simulated scenarios are characterised by the management strategy application together with different constraints setting up (see Table 2); by adding those technical limitations, the dwellings' capacity to participate in flexibility mechanisms is lessened.

The RF indicator use allows the authors to properly examine each scenario proposed by the authors. Indeed, once the RF variations associated to the archetypes over different months are known, it is possible to provide a realistic overview of potential flexibility. Table 4 summarises $N_{F l e x, S x}$ annual values for the selected archetypes, when the proposed scenarios have been accounted for.

Table 4. Archetypes $N_{\text {Flex,Sx }}$ by applying the Load Shifting strategy.

\begin{tabular}{|c|c|c|c|c|c|c|c|c|c|c|c|c|c|c|}
\hline \multirow{2}{*}{ Parameters } & \multicolumn{14}{|c|}{ Archetype } \\
\hline & $\# 1$ & $\# 2$ & $\# 3$ & $\# 4$ & $\# 5$ & $\# 6$ & $\# 7$ & $\# 8$ & $\# 9$ & $\# 10$ & $\# 11$ & $\# 12$ & $\# 13$ & \#14 \\
\hline$N_{\text {Flex }, \mathrm{S} 0}$ & 840 & 379 & 1030 & 172 & 1365 & 1261 & 1019 & 246 & 633 & 289 & 1868 & 650 & 984 & 504 \\
\hline$N_{\text {Flex }, \mathrm{S} 1}$ & 432 & 236 & 526 & 83 & 753 & 534 & 769 & 160 & 334 & 194 & 1218 & 494 & 581 & 315 \\
\hline$N_{\text {Flex }, \mathrm{S} 2}$ & 430 & 236 & 520 & 83 & 740 & 425 & 765 & 160 & 334 & 194 & 1216 & 492 & 560 & 315 \\
\hline$N_{\text {Flex }, \mathrm{S} 3}$ & 339 & 236 & 201 & 83 & 661 & 386 & 684 & 160 & 265 & 167 & 1216 & 463 & 466 & 266 \\
\hline$N_{\text {Flex }, \mathrm{S} 4}$ & 304 & 222 & 195 & 81 & 609 & 322 & 636 & 138 & 257 & 144 & 1037 & 414 & 367 & 259 \\
\hline
\end{tabular}

According to what is reported in Table 4, the annual RF values vs. archetypes, with changes in scenarios, were calculated and are plotted in Figure 5. From data, it emerges how the more restrictive constraints applied in S2, S3 and S4 scenarios, lead to significant reductions of RF values. 


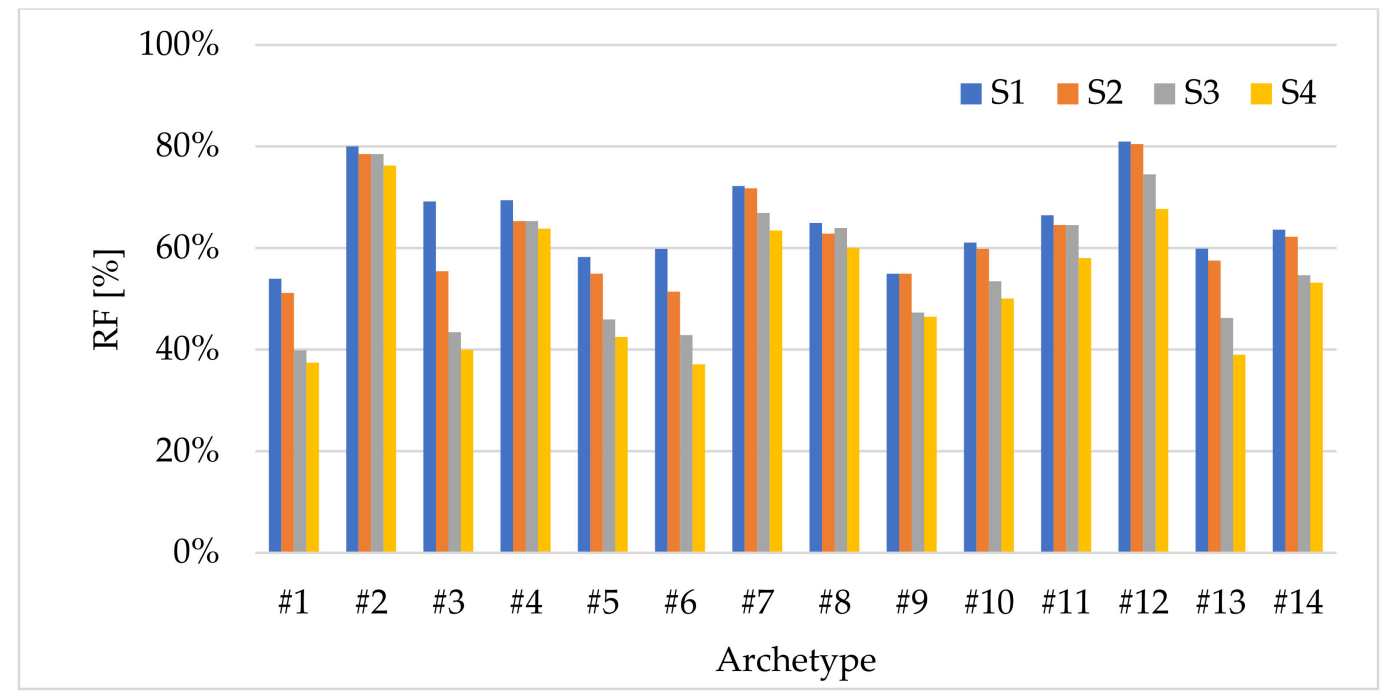

Figure 5. RF: archetype annual average values.

Specifically, $\mathrm{RF}^{\prime} \mathrm{s}$ decrease from an average value of $66 \%$ once no limitation is applied in scenario (S1), to 53\% taking into account all constraints in S4; moreover, a strong $\mathrm{RF}$ reduction has been registered between scenario $\mathrm{S} 2(\mathrm{RF}=62 \%)$ and $\mathrm{S} 3(\mathrm{RF}=56 \%)$, since limiting the energy-intensive appliances (i.e., washing machine, dish washer, air conditioner) hinders an effective load shifting of their cycles. Furthermore, that reduction is higher for those archetypes characterised by low RF values (e.g., \#1, \#3, \#5, \#6, \#13). It is due to the fact that they largely use such appliances, and they are more affected by the constraint's introduction than the other archetypes.

Table 5 reports the $N_{\text {Flex,Sx }}$ monthly values in each scenario, having considered the 14 archetypes combination (i.e., summing all their contributions).

Table 5. Monthly $N_{\text {Flex,Sx }}$ by applying the Load Shifting strategy.

\begin{tabular}{|c|c|c|c|c|c|c|c|c|c|c|c|c|}
\hline \multirow{2}{*}{ Parameters } & \multicolumn{12}{|c|}{ Months } \\
\hline & Jan & Feb & Mar & Apr & May & Jun & Jul & Aug & Sept & Oct & Nov & Dec \\
\hline$N_{\text {Flex }, \mathrm{S} 0}$ & 1878 & 1065 & 872 & 1235 & 924 & 640 & 792 & 597 & 1088 & 547 & 680 & 934 \\
\hline$N_{\text {Flex }, \mathrm{S} 1}$ & 1220 & 693 & 589 & 795 & 603 & 404 & 301 & 234 & 561 & 356 & 425 & 515 \\
\hline$N_{\text {Flex }, \mathrm{S} 2}$ & 1205 & 693 & 586 & 777 & 601 & 395 & 282 & 188 & 501 & 354 & 423 & 515 \\
\hline$N_{\text {Flex }, \mathrm{S} 3}$ & 906 & 634 & 510 & 619 & 514 & 358 & 262 & 160 & 470 & 329 & 369 & 456 \\
\hline$N_{\text {Flex }, \mathrm{S} 4}$ & 677 & 578 & 464 & 510 & 467 & 325 & 250 & 158 & 433 & 295 & 326 & 409 \\
\hline
\end{tabular}

Figure 6 depicts the monthly RF values for each scenario, when archetypes have been gathered. Here too, RF reductions have been registered owing to the increasing limitations set up, according to S2, S3 and S4. Additionally, months belonging to the summertime are usually characterised by lower values than the others. 


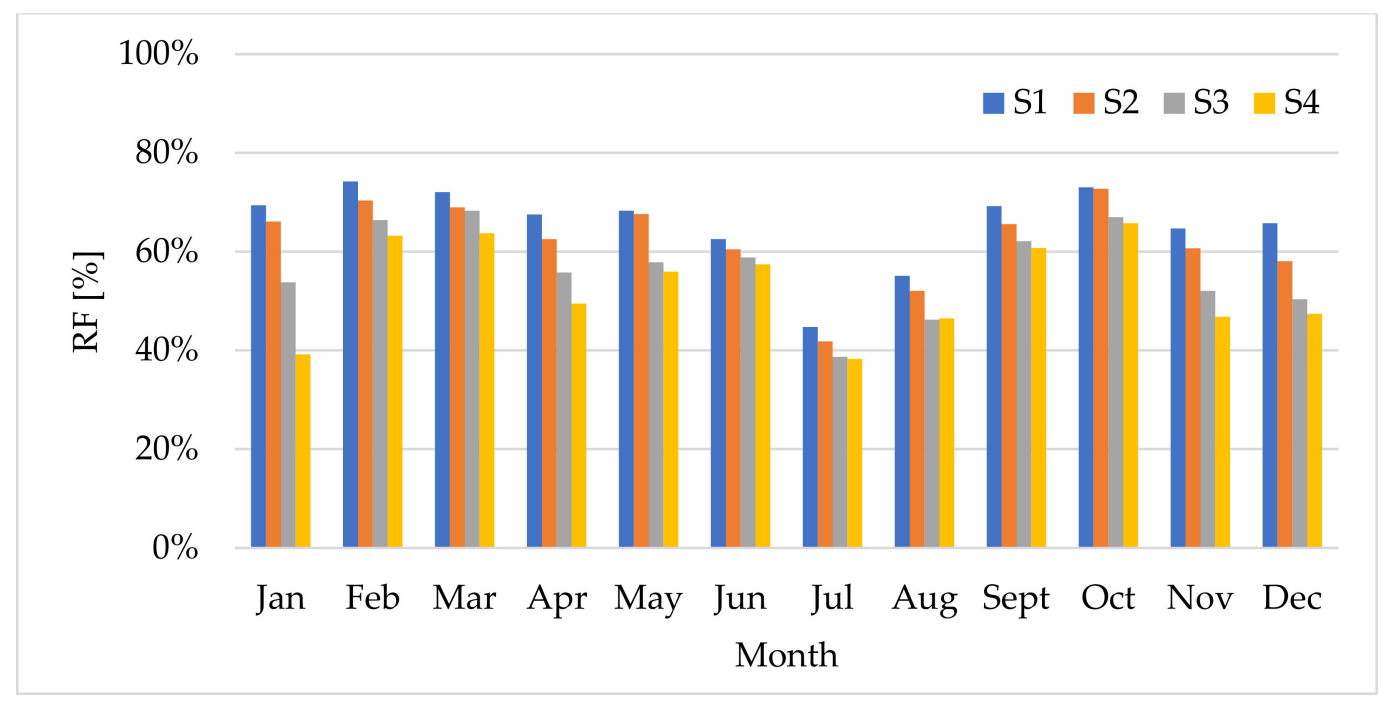

Figure 6. RF: monthly average values.

These RF reductions over the summertime depend mostly on the cooling systems operation, since the load shifting of air conditioner cycles is generally not feasible, due to the lack of suitable Load Reduction Time.

Thus, Figure 6 shows how, in June, July and August, the RF values are less sensitive to the introduction of $\mathrm{S} 4$ constraints. That behaviour is caused by climatic and time-delay factors, hailing from the larger photovoltaic power release in the national grid, and from lighting loads postponement. Moreover, the great number of Load Increase Time periods, occurring in 10:00 a.m. up to 4:00 p.m., shrinks the loads shifting needs towards night-time.

More generally, where the Load Reduction Time periods are frequent, the RF is strongly penalised by applying the S4 features. Indeed, needs of loads shifting towards night-time are greater, but 44 constraints do not allow that.

\subsection{Flexible Loads by Strategy \& Scenario: Energy Shift}

It is important to highlight that RF is a relative value accounting only for appliance cycles. Therefore, it is not an exhaustive indicator for directly comparing each other the selected archetypes. For that purpose, a thorough analysis on loads peculiarities must be carried out. In such a way, it is possible to identify how often, the archetypes showing low $\mathrm{RF}$, can provide higher flexibility in terms of energy shift (ES). For instance, referring to Figure 7, the archetypes number \#6 and \#13 are characterised by quite low ES values.

In the same way as before, for the RF indicator, Figure 8 depicts the ES average monthly values, when the archetypes have been clustered and constraint scenarios changed. That chart points out remarkable reductions in ES values over the summertime, owing to different operating mode of flexible appliances.

The archetypes' ES scattering values, sorted by months for a fixed scenario, are reported in Figures 9-12.

Comparing those charts, it is possible to recognise a progressive lowering in ES statistical distribution values over the year, as more technical limitations are added. In detail, that reduction is greater where the ES values are higher, since shifted loads are generally much more, and hence, from a statistical point of view, even the unshifted loads are higher. Additionally, that issue repeats often in the winter months, where the ES third quartile amount to $26 \mathrm{kWh} /$ month/dwelling, and peaks can get to $43 \mathrm{kWh} / \mathrm{month} /$ dwelling. By changing scenarios, those values go down until $-32.5 \%$, starting from an annual average of $27 \mathrm{kWh} /$ month/dwelling up to $18 \mathrm{kWh} /$ month/dwelling. Indeed, a high decrease is registered in wintertime, especially between the $\mathrm{S} 1$ and $\mathrm{S} 4$ scenarios. In that case, the average monthly values associated to January lessen from 40 to $17 \mathrm{kWh} / \mathrm{month} / \mathrm{dwelling}$. Differ- 
ently, the reduction in the summertime is smaller, because of the modest amount of available flexibility, such as in June, where ES decreases from 19 to $14 \mathrm{kWh} / \mathrm{month} / \mathrm{dwelling}$.

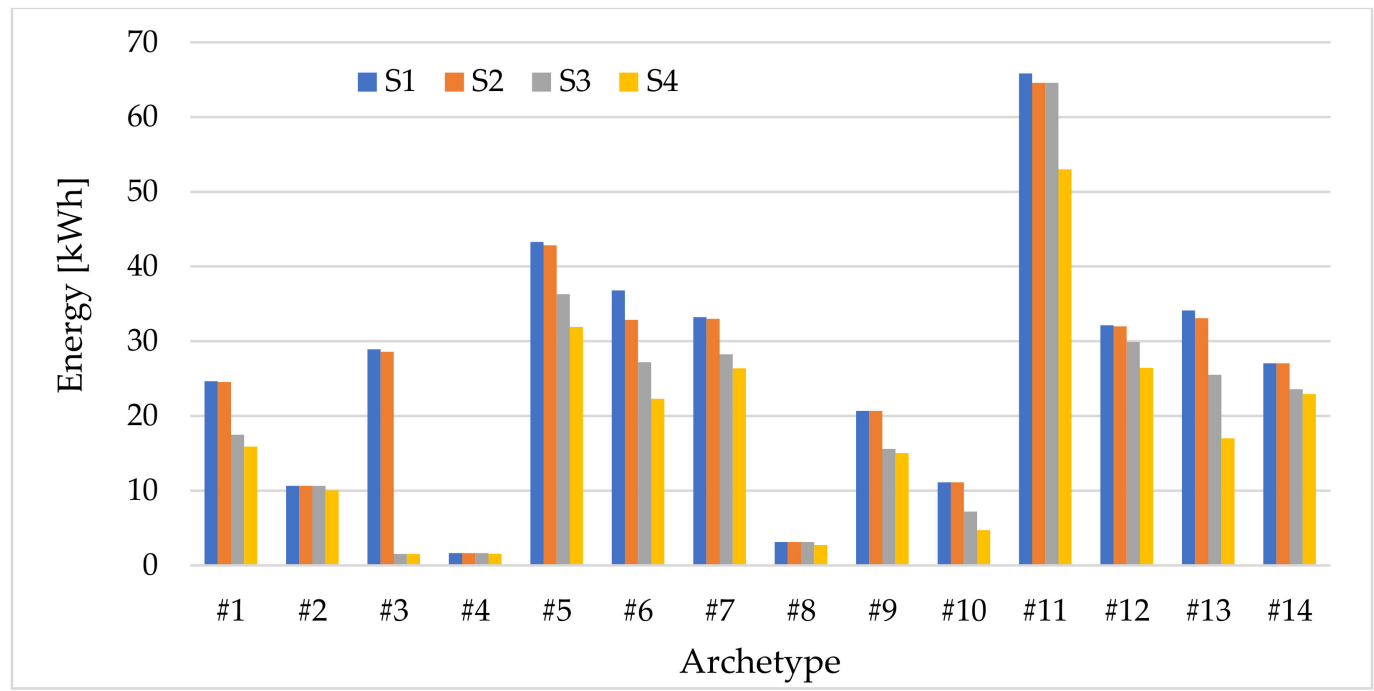

Figure 7. Archetypes average annual values of Monthly Energy Shift, with changes in constraint scenarios.

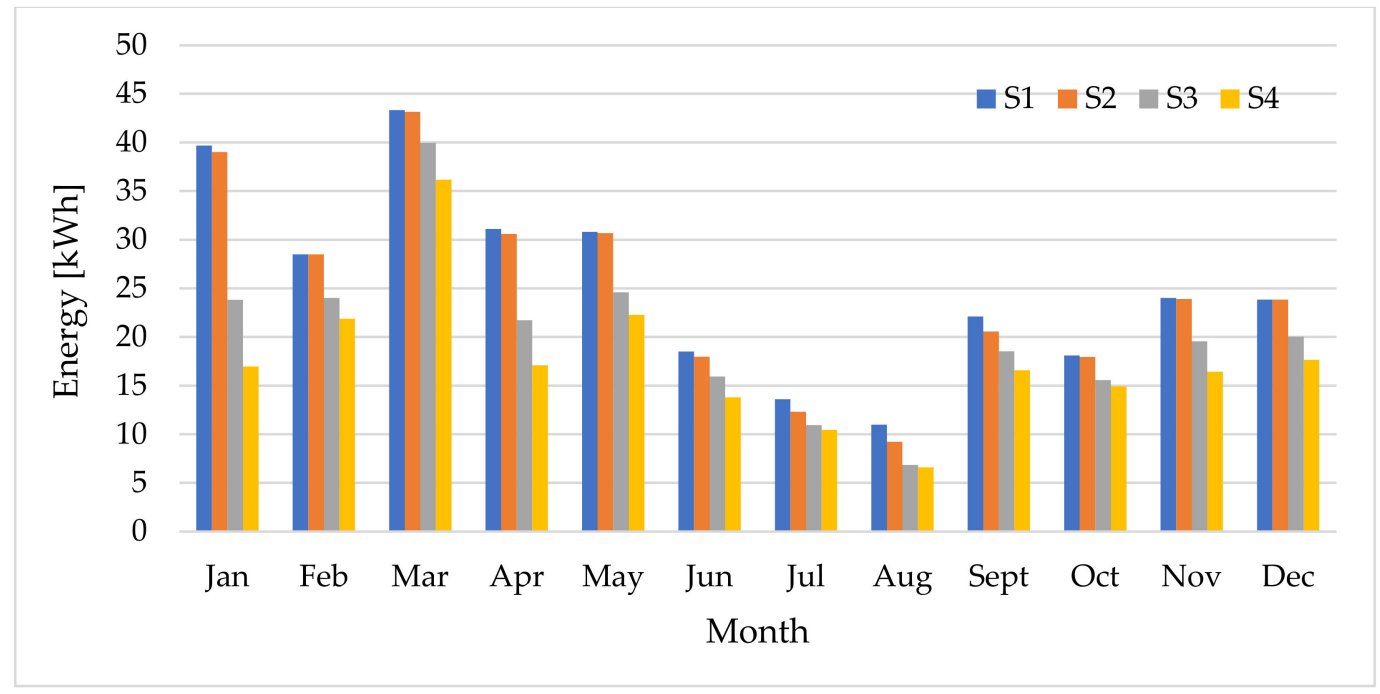

Figure 8. Clustered archetypes average Monthly Energy Shift, with changes in constraint scenarios.

The average values of monthly reduction, caused by applying technical constraints $\mathrm{C} 1, \mathrm{C} 2$ and $\mathrm{C} 3$ for simulating the S2 scenario, are not significant; conversely, the extreme limits of scattering values must be considered relevant (see Figure 10).

Introducing all of the restrictions associated to scenario S3, which mostly influence the energy-intensive appliances, the ES reductions become more evident. That feature especially occurs over the wintertime, where the ES values are greater, as reported in Figure 11. On the other hand, the average monthly variability values are mitigated, showing lower fluctuations over the whole year. 


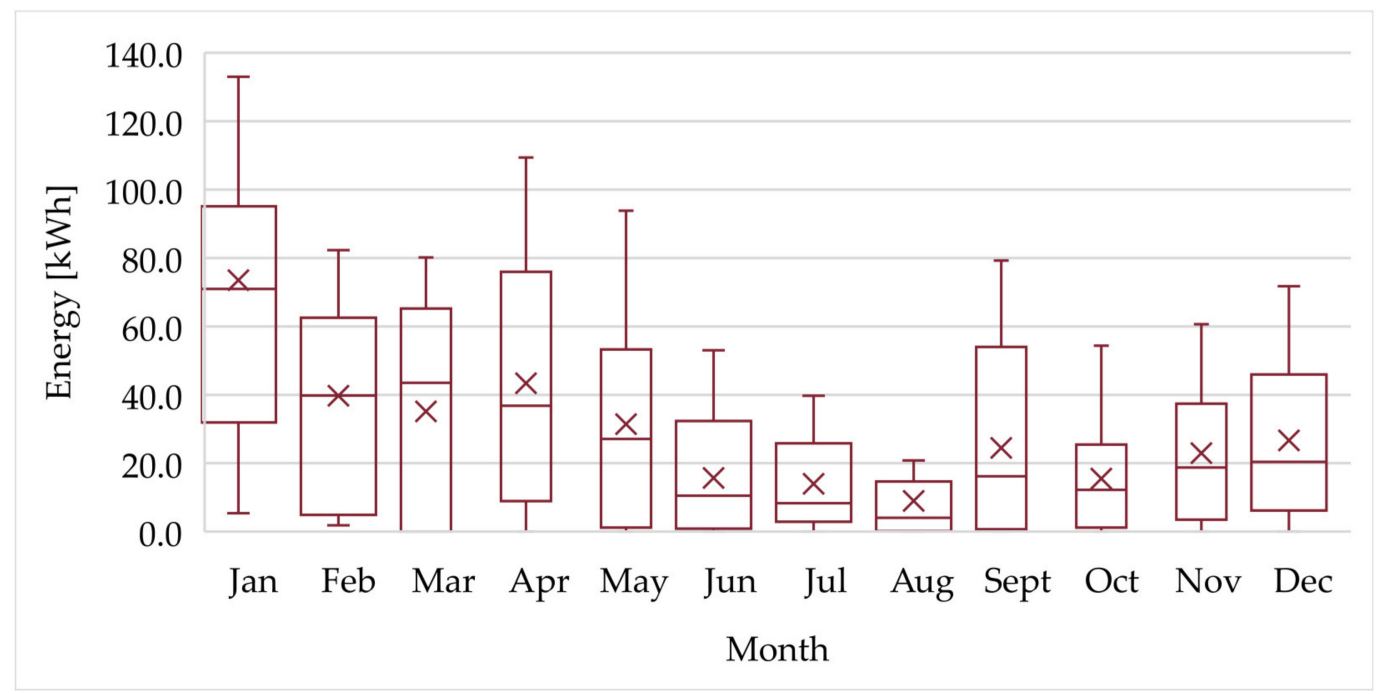

Figure 9. ES: Scenario 1, monthly average values.

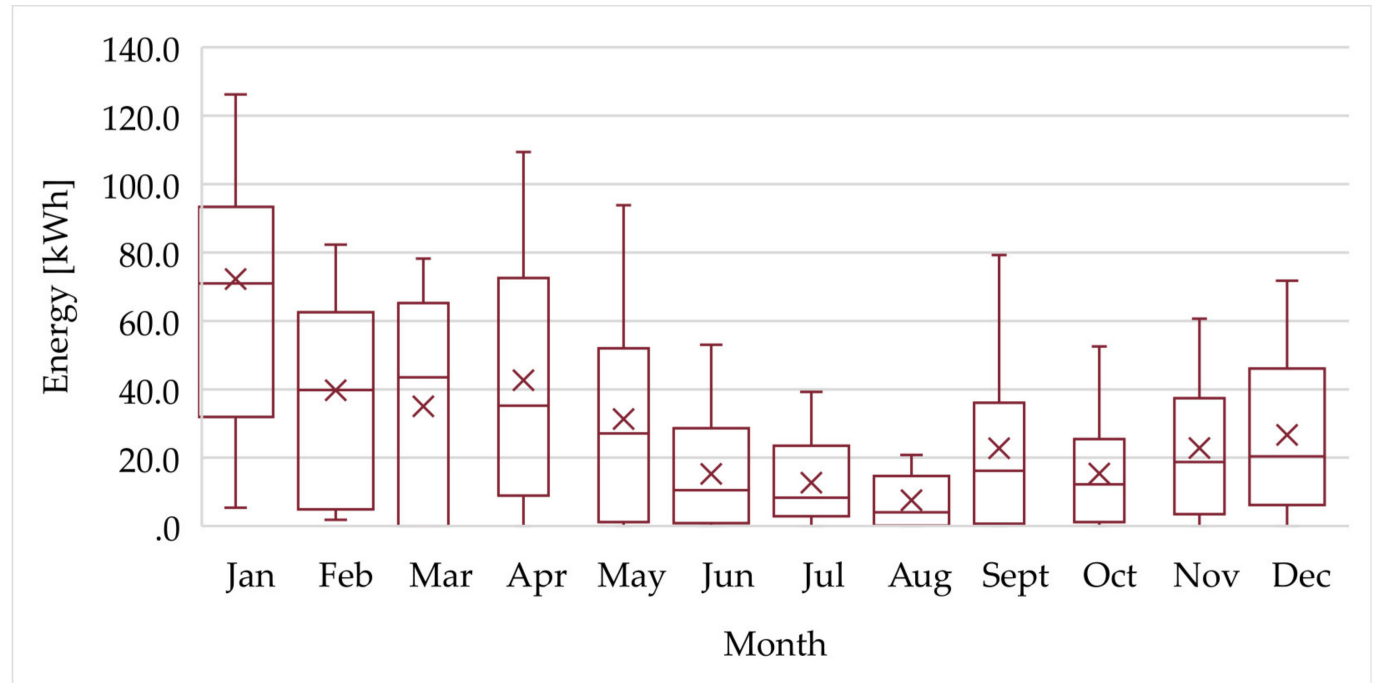

Figure 10. ES: Scenario 2, monthly average values.

Thereafter, when the most restrictive limitations are introduced by the S4 scenario, the ES monthly variability, in terms of both average and extreme scattering values, is characterised by a further lessening along with a more flattened trend. Such a behaviour, it is due to the fact that, the current technical constraints deny loads shifting through the night time (see Figure 12).

\subsection{Flexible Loads by Strategy \& Scenario: Peak Shaving}

The Peak Shaving indicator trends (i.e., PS) have been clearly plotted in Figures 13 and 14. It is worth noticing that PS is defined as the maximum registered power reduction, over a 15-min time span. That indicator is calculated for each archetype as well as for the clustered version. In so doing, it is possible to evaluate firstly the flexibility system potential, and secondly, to identify the number of minimum users able to provide the grid DSO with specific DSM parameters and references. Moreover, from Figure 13, it is possible to distinguish those archetypes using the most energy intensive appliances, so that greater DSM services might be potentially provided to the grid. In Figure 14, the monthly variation shows a modest reduction only in the summertime. The PS variability between the simulated constraint scenarios remains almost constant, highlighting the nature of 
this indicator. Indeed, it indicates a maximum value instead of an average one, as for the previous indicators. In detail, PS indicator small and quite negligible reductions are detected by applying the different scenarios, namely: $1678 \mathrm{~W}$ for S1, $1677 \mathrm{~W}$ for S2, $1612 \mathrm{~W}$ for S3, $1592 \mathrm{~W}$ for S4.

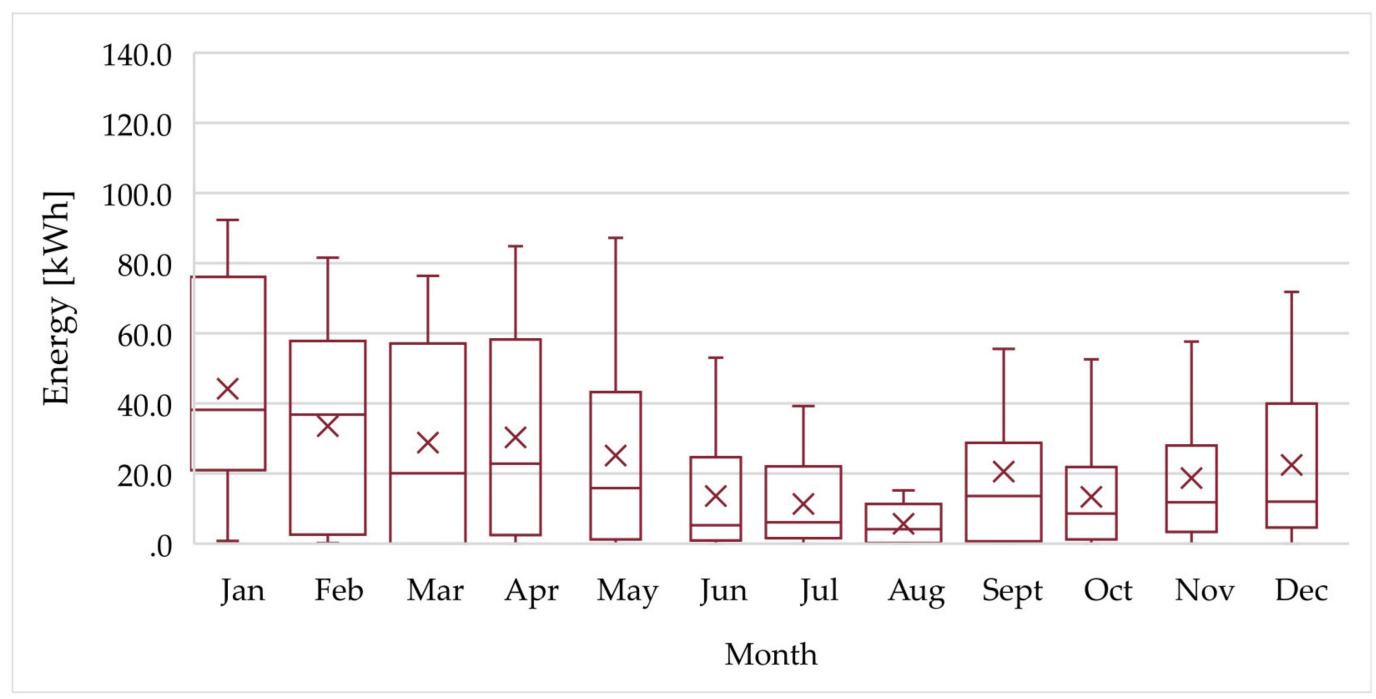

Figure 11. ES: Scenario 3, monthly average values.

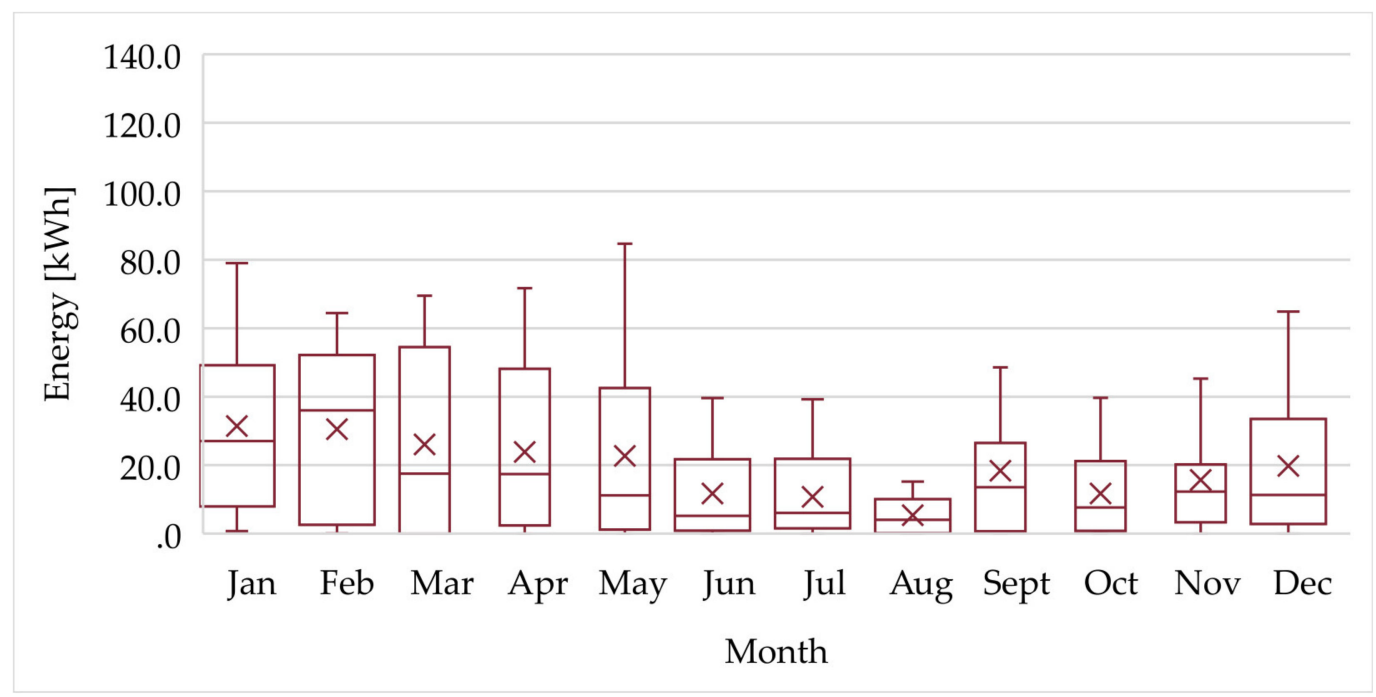

Figure 12. ES: Scenario 4, monthly average values.

The PS scattered values associated to the archetypes, sorted by months, are plotted in Figures 15-18. Those charts represent the maximum shaved power distribution, caused by the scenario Sx application. From data analysis, it is possible to conclude that the higher variations correspond to the lower PS values. That feature entails that some archetypes keep constant their PS values over the year, while the others are characterised by lower PS, generally over the summertime. Moreover, in Figure 15, it can be noticed how the median monthly values do not exceed the threshold of $2000 \mathrm{~W}$, which mostly range between $1500 \mathrm{~W}$ and $1900 \mathrm{~W}$. 


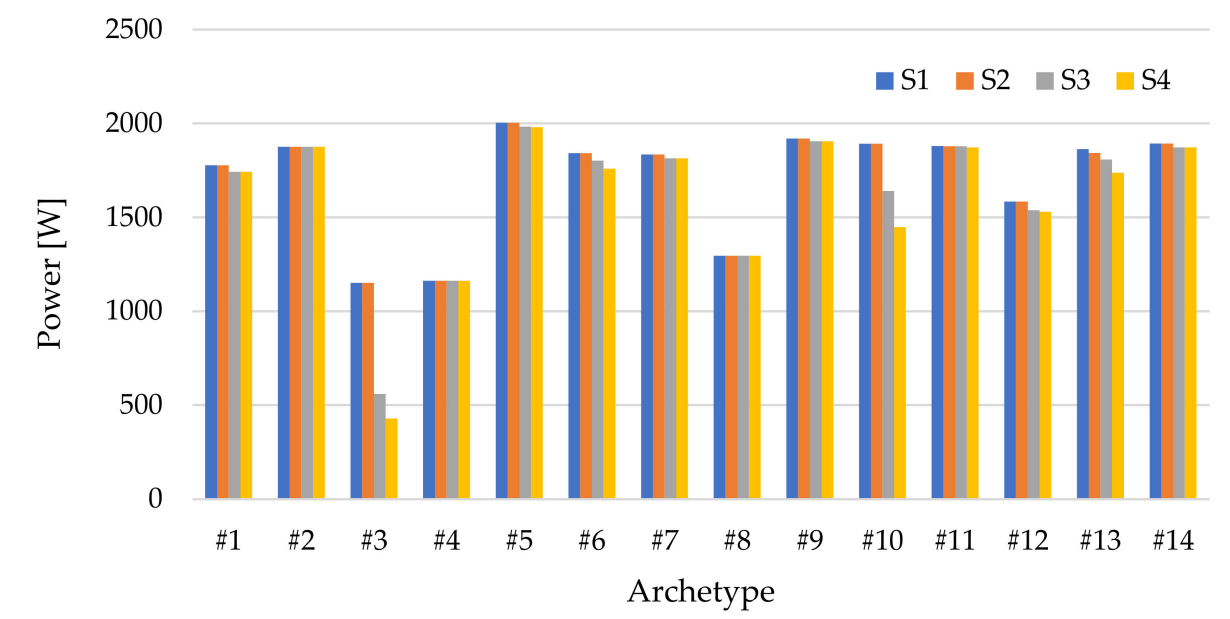

Figure 13. PS: archetype annual average values.

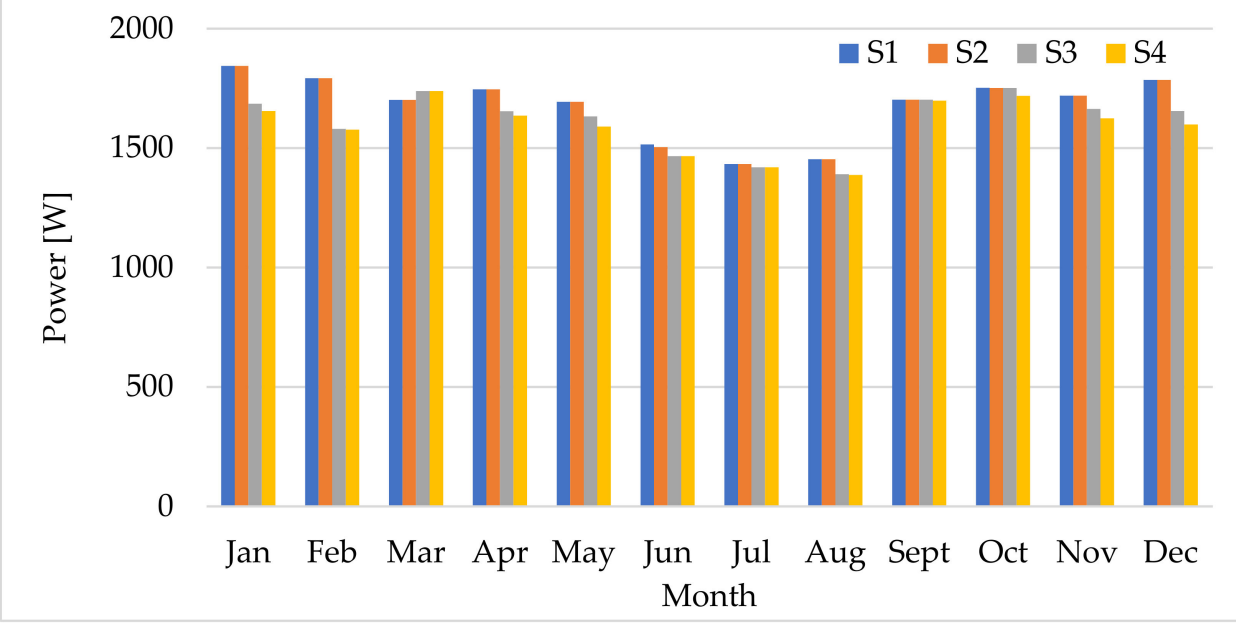

Figure 14. PS: monthly average values.

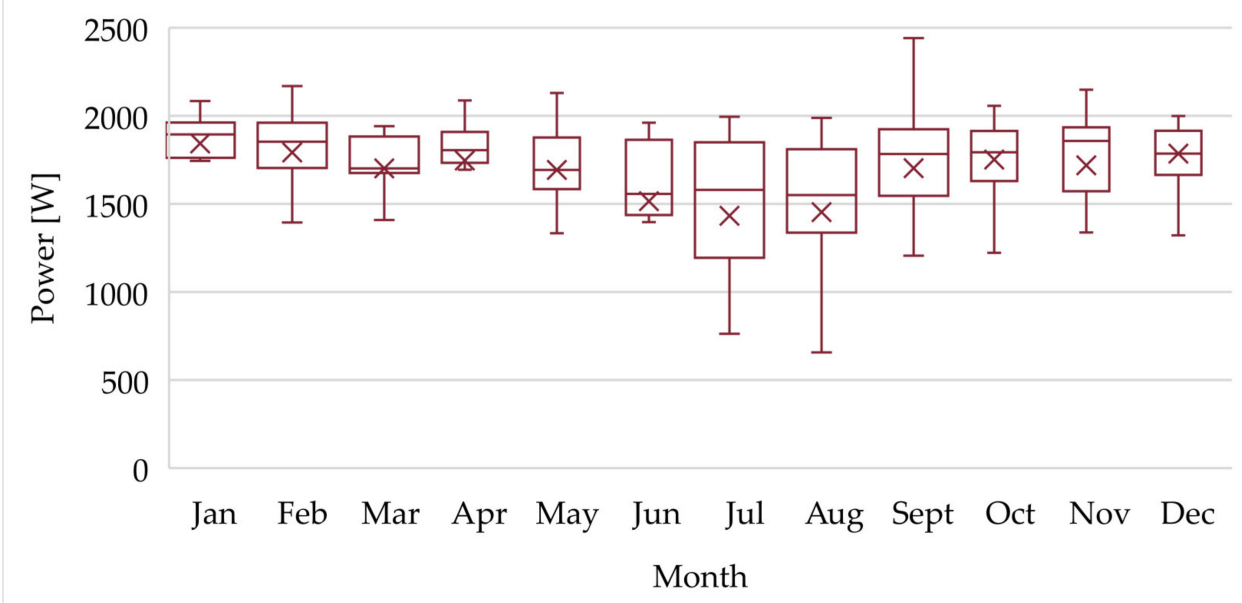

Figure 15. PS: Scenario 1, monthly average values. 


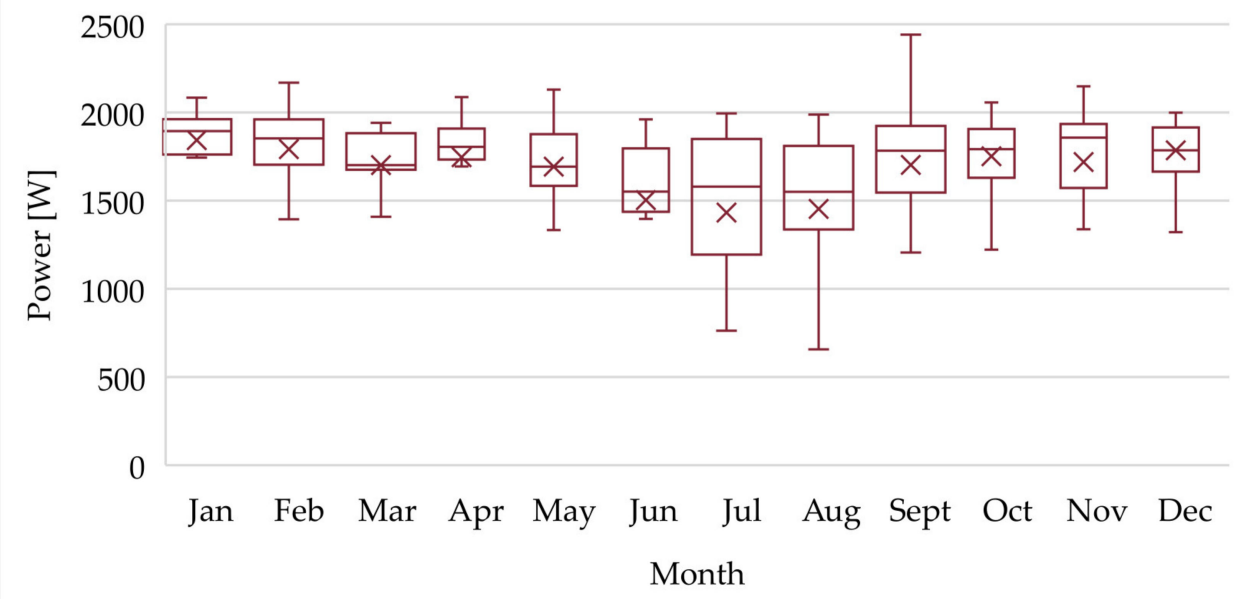

Figure 16. PS: Scenario 2, monthly average values.

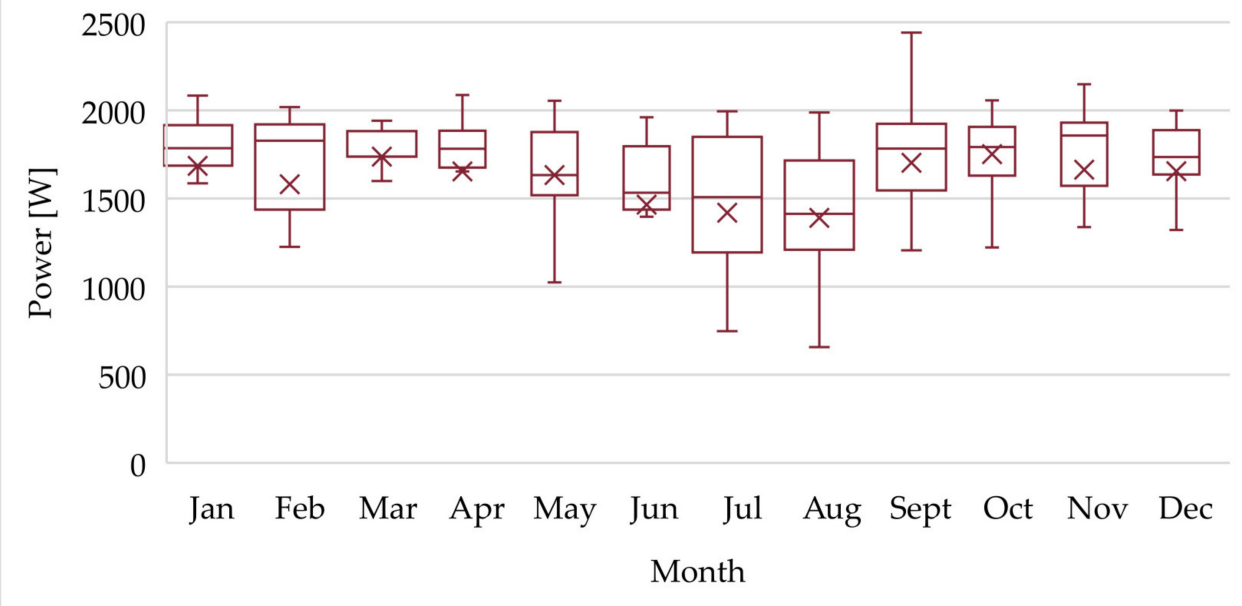

Figure 17. PS: Scenario 3, monthly average values.

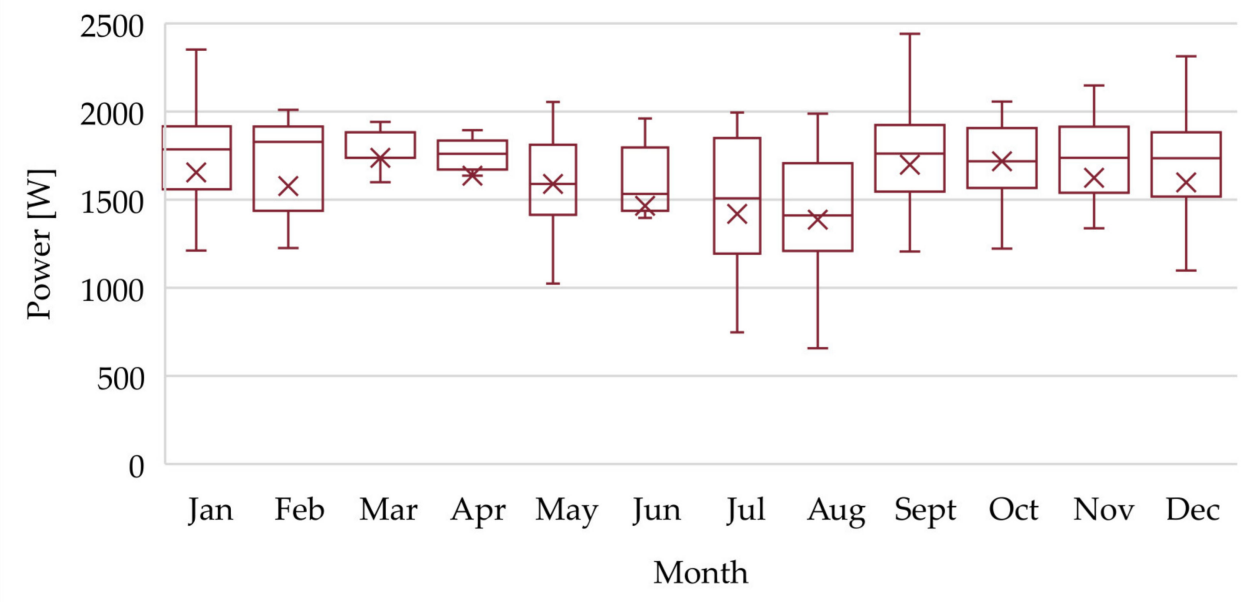

Figure 18. PS: Scenario 4, monthly average values. 
Thus, Figure 16 reports the PS variation owing to the S2 scenario application. Comparing these data with those related to the S1 scenario, small differences are registered, exception for the minimum values of the monthly scattering plot.

That issue is emphasised further within the chart associated to the S3 scenario (see Figure 17), where the minimum values further decrease (first quartile), hence the PS variation range increases (e.g., in February).

The same trend is confirmed by the S4 scenario (see Figure 18), where a modest lessening in the maximum values, together with the median and the average, occur. The average annual values drift away, starting from $1777 \mathrm{~W}$ for the S1 scenario, towards $1600 \mathrm{~W}$ for the S4 scenario.

\section{Conclusions}

This work aims at defining and quantifying the real flexibility offered by a building cluster, in the Italian residential sector, to the national grid. In so doing, that cluster can participate in a demand response program in accordance with a Flexibility Price-marketbased Strategy. Extrapolating and exploiting data collection, hailing from an experimental campaign carried out on 14 reference dwellings, over two years, a Load Shifting Strategy has been applied. Additionally, some theoretical indicators have been presented and extensively discussed on the basis of a real case study. Then, four different scenarios have been built by imposing several technical constraints on the household appliances, accounting for operation contemporaneity, building occupancy, cycles time sequences etc. All of scenarios are characterised by a growing limitation degree in the Load Shifting strategy, which consequently causes considerable reduction of Real Flexibility capacity that a building cluster can provide.

In order to evaluate the potential reduction hailing from the realistic constraints, a reference scenario S0 has been built. It represents the theoretical Flexibility potential. In detail, scenario S1 includes only the Load Shifting Strategy application; in scenarios, S2-S4 seven technical constraints have been added. Starting from the RF average value over the year equal to $66 \%$, it decreases up to $53 \%$, with seasonal differences which get the lowest values in July and August. RF values up to $80 \%$, can be provided by some sample dwellings. Notwithstanding, when buildings are clustered, the virtuous end users' habits can be mitigated, leading to lower flexibility capacity associated to the residential sector.

Other indicators have been calculated, and one of these is the ES (energy amount effectively moved over the day deriving from the Load Shifting strategy). Monthly average values of ES decrease from 12 to $8 \mathrm{kWh} /$ month/dwelling, due to the more restrictive scenario application (i.e., S4). ES peak values have been calculated and $35 \mathrm{kWh} / \mathrm{month} / \mathrm{dwelling}$ has been accomplished. The PS indicator has been calculated too: values close to $1600 \mathrm{~W}$, with a low sensitivity to the different scenarios, show moderate effects in terms of power reduction; nevertheless, by gathering some dwellings, it is possible to get to higher PSs for providing the grid with an efficient strategy to reshape the load curve.

The main outcomes from simulation can be outlined as follows:

- $\quad$ The RF value shrinks as the constraints number increases; starting from S1 to S4 the registered $\mathrm{RFs}$ are equal to $66 \% ; 62 \% ; 56 \% ; 53 \%$, respectively.

- The ES value decreases by changing scenarios; from S1 to S4, 27; $26 ; 21 ; 18 \mathrm{kWh} / \mathrm{month} /$ dwelling, have been registered, respectively.

- The value of PS does not significantly decrease, from S1 to S4, e.g., 1678 W; 1677 W; $1612 \mathrm{~W} ; 1592 \mathrm{~W}$, respectively.

- The appliances' cycles are mostly shifted in the afternoon, between 4:00 p.m. and 8:00 p.m.; the time span in which they are moved is close to the late evening and night-time. As regards the S4 scenario, the loads shifting occurs early in the morning (after 6:00 a.m.).

- The Dish Washer and Washing Machine cycles that generally are shifted, have an energy consumption approximately equal to $1 \mathrm{kWh} /$ cycle. 
- In the summertime (from June to September) flexibility is on the average lower than in the other months, in terms of both RF and ES, because of the different composition of summer loads (e.g., lighting, air conditioning).

- The indicators values reduction is stronger in S2 and S3 rather than in the other scenarios. That is due to the restrictive limitations addition which have been applied to the energy-intensive appliances.

This article is presented based on the actual data of 14 homes, which are characterised by a low electrification degree; among those, only one reference home is equipped with a photovoltaic plant. New scenarios are being developed dealing with dwellings which use heat pumps for heating and DHW purpose, and which have self-generation hailing from $\mathrm{PV}$ along with batteries pack. In these cases, self-generation and storage devices constitute further constraints compared to those examined in this article. As a result, the flexibility potential that each individual dwelling can offer to the electric spot market will be reduced.

Author Contributions: F.M. contributed to this paper by the conceptualization and validation; G.L.B. provided the formal analysis and was the writer of the final draft along with the reviewing and editing process; J.C. was the responsible for data collection, their postprocessing and software implementation; F.M. and S.R. were the project scientific coordinators: the former was responsible of funding acquisition along with project administration; the latter was the general project supervisor. All authors have read and agreed to the published version of the manuscript.

Funding: This research received no external funding.

Acknowledgments: This work is a part of a wider research activity dealing with: "Technologies for efficient use and deployment of electric energy carrier". The project has been carried out in cooperation with ENEA-DTE (Italian National Agency for New Technologies, Energy and Sustainable Economic Development-Department of Energy Technologies) and CITERA (Sapienza University of Rome-Interdepartmental Research Centre for Territory, Construction, Restoration and Environment). The aforementioned institutions are gratefully acknowledged by the authors for their support and funding.

Conflicts of Interest: The authors declare no conflict of interest.

\section{Appendix A}

Table A1. Strategy to optimise the load shifting: weekdays; (-2, Green) Strong Load reduction; ( -1 , Light Green) Weak Load re-duction; (0, White) No Load variation; (1, Light Red) Weak Load increase; (2, Red) Strong Load increase.

\begin{tabular}{|c|c|c|c|c|c|c|c|c|c|c|c|c|c|c|c|c|c|c|c|c|c|c|c|c|}
\hline \multirow{2}{*}{ Months } & \multicolumn{24}{|c|}{ Hours } \\
\hline & 1 & 2 & 3 & 4 & 5 & 6 & 7 & 8 & 9 & 10 & 11 & 12 & 13 & 14 & 15 & 16 & 17 & 18 & 19 & 20 & 21 & 22 & 23 & 24 \\
\hline January & 1 & 2 & 2 & 2 & 2 & 2 & 1 & -1 & -2 & 0 & 0 & 0 & 1 & 0 & 0 & -1 & 0 & -1 & -1 & -2 & -1 & -1 & 0 & 0 \\
\hline February & 2 & 2 & 2 & 2 & 2 & 2 & -1 & -1 & -1 & 0 & 0 & 1 & 1 & 1 & 1 & -1 & -1 & -1 & -1 & -2 & -2 & -1 & 0 & 0 \\
\hline March & 1 & 2 & 2 & 2 & 2 & 2 & -1 & -1 & -1 & 0 & 0 & 1 & 1 & 1 & 0 & -1 & -1 & 0 & -1 & -2 & -2 & -1 & 0 & 0 \\
\hline April & 1 & 2 & 2 & 2 & 2 & 2 & 1 & -1 & -1 & 0 & 0 & 0 & 1 & 1 & 0 & 0 & -1 & -1 & -1 & -2 & -2 & -2 & -1 & 0 \\
\hline May & 1 & 2 & 2 & 2 & 2 & 2 & 1 & -2 & -1 & 0 & 0 & 0 & 1 & 0 & 0 & 0 & -1 & 0 & -1 & -2 & -2 & -2 & -1 & 0 \\
\hline June & 1 & 2 & 2 & 2 & 2 & 2 & 1 & -1 & 0 & 0 & 0 & 1 & 1 & 0 & 0 & -1 & -1 & -1 & -1 & -2 & -2 & -2 & -1 & 0 \\
\hline July & 0 & 1 & 2 & 2 & 2 & 2 & 2 & 1 & 0 & 0 & 0 & 0 & 1 & 0 & 0 & -1 & -1 & -1 & -2 & -2 & -2 & -2 & -1 & 0 \\
\hline August & -1 & 1 & 2 & 2 & 2 & 2 & 2 & 1 & 0 & 0 & 1 & 1 & 1 & 0 & 0 & -1 & -1 & -2 & -1 & -1 & -2 & -2 & -1 & -1 \\
\hline September & 1 & 2 & 2 & 2 & 2 & 2 & 1 & -1 & 0 & -1 & 0 & 0 & 1 & 1 & 0 & -1 & -1 & -1 & -1 & -2 & -2 & -1 & 0 & 0 \\
\hline October & 2 & 2 & 2 & 2 & 2 & 2 & 1 & -1 & -1 & -1 & 0 & 0 & 1 & 1 & 1 & -1 & -1 & -1 & -1 & -2 & -2 & -1 & 0 & 0 \\
\hline November & 2 & 2 & 2 & 2 & 2 & 2 & 1 & -1 & -1 & 0 & 0 & -1 & 1 & 1 & 0 & -1 & -1 & -1 & -1 & -2 & -1 & 0 & 0 & 0 \\
\hline December & 2 & 2 & 2 & 2 & 2 & 2 & 1 & -1 & 0 & -1 & 0 & 0 & 1 & 1 & -1 & -1 & -1 & -2 & -2 & -2 & -1 & 0 & 0 & 0 \\
\hline
\end{tabular}


Table A2. Strategy to optimise the load shifting: Saturdays. (-2, Green) Strong Load reduction; ( -1 , Light Green) Weak Load reduction; (0, White) No Load variation; (1, Light Red) Weak Load increase; (2, Red) Strong Load increase.

\begin{tabular}{|c|c|c|c|c|c|c|c|c|c|c|c|c|c|c|c|c|c|c|c|c|c|c|c|c|}
\hline \multirow{2}{*}{ Months } & \multicolumn{24}{|c|}{ Hours } \\
\hline & 1 & 2 & 3 & 4 & 5 & 6 & 7 & 8 & 9 & 10 & 11 & 12 & 13 & 14 & 15 & 16 & 17 & 18 & 19 & 20 & 21 & 22 & 23 & 24 \\
\hline January & 1 & 2 & 2 & 2 & 2 & 2 & 1 & 0 & 0 & -1 & -1 & 0 & 1 & 0 & 0 & 0 & -1 & -1 & -2 & -2 & -2 & -1 & -1 & 1 \\
\hline February & 1 & 1 & 2 & 2 & 2 & 2 & 1 & 0 & 0 & -1 & -1 & 0 & 1 & 0 & 0 & 0 & -1 & -1 & -1 & -1 & -2 & -1 & -1 & 1 \\
\hline March & 0 & 1 & 1 & 2 & 2 & 1 & 0 & 0 & 0 & -1 & -1 & 1 & 0 & 0 & 0 & 0 & 0 & 0 & 0 & -2 & -2 & -2 & -1 & 0 \\
\hline April & 0 & 1 & 1 & 1 & 2 & 1 & 0 & 0 & 0 & -2 & -1 & 1 & 0 & 0 & 0 & 0 & 0 & 0 & 0 & -2 & -2 & -2 & -1 & 0 \\
\hline May & 0 & 0 & 1 & 2 & 2 & 2 & 1 & 0 & 0 & -1 & 0 & 0 & 0 & 0 & 0 & 0 & 0 & 0 & $\overline{-1}$ & -1 & -2 & -2 & -1 & 1 \\
\hline June & 0 & 0 & 0 & 1 & 1 & 1 & 1 & 1 & 0 & -1 & 0 & 1 & 0 & 0 & 0 & 0 & 0 & 0 & -1 & -2 & -2 & -2 & -2 & 0 \\
\hline July & 0 & 0 & 0 & 0 & 1 & 1 & 1 & 1 & 0 & -1 & 0 & 0 & 0 & 0 & 0 & 0 & 0 & 0 & -1 & -1 & 0 & 0 & 0 & -1 \\
\hline August & -1 & 0 & 0 & 0 & 1 & 1 & 1 & 1 & 0 & 1 & 1 & 0 & 1 & 0 & 0 & 0 & 0 & -1 & 0 & -1 & -2 & -1 & -2 & -1 \\
\hline September & 0 & 0 & 1 & 1 & 1 & 1 & 0 & 0 & 0 & 0 & 0 & 0 & 0 & 0 & 0 & 1 & 0 & -1 & -1 & -2 & -2 & -2 & -1 & 1 \\
\hline October & 0 & 0 & 1 & 1 & 2 & 1 & 0 & 0 & -1 & -1 & 0 & 1 & 0 & 0 & 0 & 1 & 0 & -1 & 0 & -2 & -2 & -1 & 0 & 0 \\
\hline November & 1 & 1 & 1 & 2 & 2 & 2 & 1 & 0 & 0 & -1 & -1 & 0 & 0 & 0 & 0 & 0 & -2 & -2 & -1 & -1 & -2 & -1 & 0 & 1 \\
\hline December & 1 & 1 & 2 & 2 & 2 & 2 & 2 & 0 & 0 & -1 & -1 & 0 & 1 & 1 & 0 & -1 & -2 & -2 & -1 & -2 & -2 & -1 & 0 & 0 \\
\hline
\end{tabular}

Table A3. Strategy to optimise the load shifting: non-working days. (-2, Green) Strong Load reduction; ( -1 , Light Green) Weak Load reduction; (0, White) No Load variation; (1, Light Red) Weak Load increase; (2, Red) Strong Load increase.

\begin{tabular}{|c|c|c|c|c|c|c|c|c|c|c|c|c|c|c|c|c|c|c|c|c|c|c|c|c|}
\hline \multirow{2}{*}{ Months } & \multicolumn{24}{|c|}{ Hours } \\
\hline & 1 & 2 & 3 & 4 & 5 & 6 & 7 & 8 & 9 & 10 & 11 & 12 & 13 & 14 & 15 & 16 & 17 & 18 & 19 & 20 & 21 & 22 & 23 & 24 \\
\hline January & 0 & 1 & 2 & 2 & 2 & 2 & 2 & 2 & 1 & 1 & -1 & -1 & -1 & 0 & 0 & 0 & -2 & -1 & -1 & -2 & -2 & -2 & -1 & 1 \\
\hline February & 0 & 1 & 2 & 2 & 2 & 2 & 1 & 1 & 0 & 0 & -1 & 0 & 0 & 0 & 0 & 0 & -1 & 0 & -1 & -2 & -2 & -2 & -2 & 0 \\
\hline March & -1 & 1 & 2 & 2 & 2 & 2 & 1 & 1 & 1 & -1 & -1 & -1 & 0 & 1 & 0 & 0 & -1 & 0 & 0 & -2 & -2 & -1 & -1 & 0 \\
\hline April & 0 & 1 & 1 & 1 & 1 & 0 & 0 & 0 & 0 & -1 & 0 & 0 & 0 & 1 & 1 & 1 & 0 & 0 & -1 & -2 & -2 & -2 & -2 & $\overline{-1}$ \\
\hline May & 0 & 0 & 1 & 2 & 1 & 0 & 1 & 1 & 0 & 0 & -1 & 0 & 0 & 0 & 0 & 0 & 0 & 1 & 0 & -1 & -2 & -2 & -2 & -1 \\
\hline June & 0 & 0 & 0 & 1 & 1 & 1 & 2 & 1 & 1 & 1 & -1 & 1 & 1 & 0 & 0 & 0 & -1 & -1 & -1 & -2 & -2 & -2 & -2 & $\overline{-1}$ \\
\hline July & -1 & 0 & 0 & 0 & 0 & 1 & 2 & 1 & 1 & 0 & 1 & 1 & 1 & 0 & 0 & 0 & 0 & -1 & -1 & -1 & -2 & -1 & -1 & 0 \\
\hline August & 0 & 0 & 0 & 0 & 1 & 0 & 1 & 1 & 1 & 1 & 1 & 0 & 1 & 0 & 0 & 0 & 0 & -1 & -1 & -1 & -1 & -2 & -1 & -1 \\
\hline September & 0 & 0 & 1 & 2 & 2 & 2 & 0 & 1 & 1 & -1 & 0 & 1 & 0 & 0 & 0 & 0 & 0 & -1 & -2 & -2 & -2 & -2 & -1 & 0 \\
\hline October & 0 & 1 & 1 & 2 & 2 & 2 & 1 & 1 & 0 & -1 & -1 & 0 & 0 & 0 & 0 & 0 & 0 & 0 & -1 & -2 & -2 & -2 & -1 & 0 \\
\hline November & 1 & 2 & 2 & 2 & 2 & 2 & 2 & 1 & 1 & 1 & -1 & 0 & 0 & 0 & -1 & -1 & -1 & -1 & -2 & -2 & -2 & -2 & -1 & 0 \\
\hline December & 1 & 1 & 2 & 2 & 2 & 2 & 2 & 1 & 1 & -1 & -1 & -1 & -1 & 1 & 1 & -1 & -2 & -1 & -2 & -2 & -2 & -2 & -1 & 1 \\
\hline
\end{tabular}




\section{Appendix B}

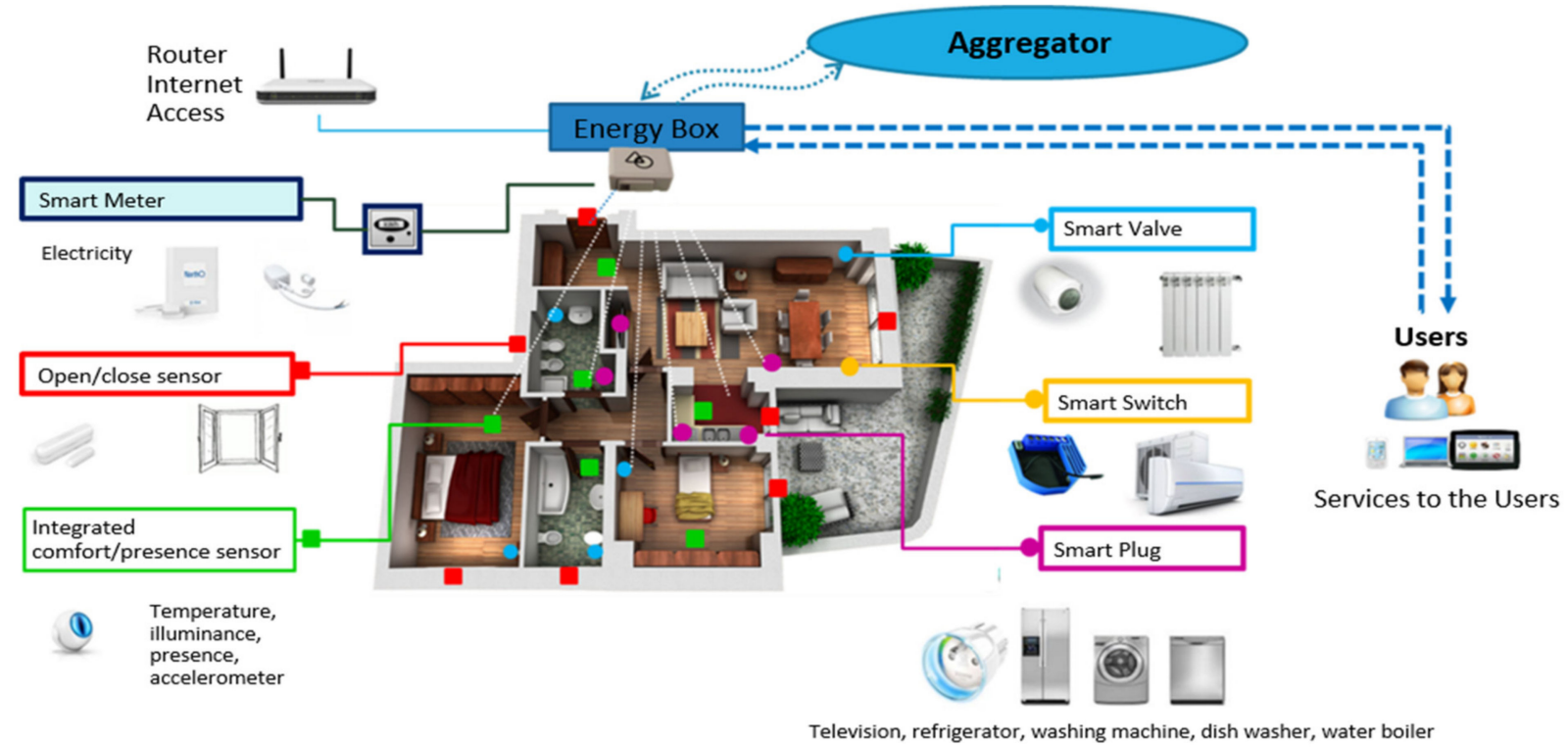

Figure A1. Control kit layout.

Table A4. Control kits configuration for the archetypes.

\begin{tabular}{|c|c|c|c|c|c|c|c|c|c|c|c|c|c|c|c|}
\hline \multirow{2}{*}{ Function } & \multirow{2}{*}{ Device } & \multicolumn{14}{|c|}{ Archetype } \\
\hline & & $\# 1$ & \#2 & $\# 3$ & $\# 4$ & $\# 5$ & $\# 6$ & $\# 7$ & $\# 8$ & $\# 9$ & $\# 10$ & $\# 11$ & $\# 12$ & $\# 13$ & $\# 14$ \\
\hline Energy box & Gateway & 1 & 1 & 1 & 1 & 1 & 1 & 1 & 1 & 1 & 1 & 1 & 1 & 1 & 1 \\
\hline \multirow{3}{*}{ Monitoring } & Electricity meters & 1 & 1 & 1 & 1 & 2 & 1 & 1 & 1 & 1 & 1 & 1 & 1 & 1 & 2 \\
\hline & $\begin{array}{l}\text { Multi-sensors } \\
\text { (temperature, } \\
\text { presence, brightness) }\end{array}$ & 5 & 6 & 6 & 4 & 6 & 6 & 4 & 4 & 7 & 6 & 3 & 9 & 7 & 7 \\
\hline & $\begin{array}{l}\text { Windows/doors } \\
\text { opening and closing } \\
\text { detectors }\end{array}$ & 7 & 8 & 6 & 5 & 8 & 8 & 5 & 5 & 10 & 10 & 6 & 9 & 12 & 9 \\
\hline \multirow{3}{*}{ Control } & Smart Valves & 6 & 5 & 0 & 4 & 3 & 6 & 5 & 3 & 8 & 6 & 0 & 0 & 7 & 0 \\
\hline & Smart Plugs & 4 & 3 & 4 & 4 & 3 & 4 & 4 & 3 & 3 & 4 & 3 & 5 & 3 & 6 \\
\hline & Smart Switches & 1 & 0 & 0 & 0 & 1 & 1 & 1 & 1 & 1 & 1 & 0 & 1 & 0 & 0 \\
\hline
\end{tabular}

Table A5. Archetypes appliances and characteristics.

\begin{tabular}{|c|c|c|c|c|c|c|c|}
\hline Archetype & Floor Surface $\left[\mathrm{m}^{2}\right]$ & Heating and DHW * & Cooling * & PV Array & $\mathbf{W M} * *$ & DW ** & TD ** \\
\hline$\# 1$ & 49 & NCB & $2 \mathrm{HP}$ & & $7 ; 5 ; \mathrm{A}+$ & $6 ; 7 ; \mathrm{A}$ & \\
\hline$\# 2$ & 101 & $\mathrm{NCB}$ & $1 \mathrm{HP}$ & & $10 ; 2.5 ; \mathrm{A}$ & & \\
\hline$\# 3$ & 100 & NCB & $1 \mathrm{HP}$ & & $7 ; 5 ; \mathrm{A}+$ & & \\
\hline$\# 4$ & 50 & $\mathrm{NCB}$ & $1 \mathrm{HP}$ & & $7 ; 1.5 ; \mathrm{A}+$ & & $5 ; 0.5 ; \mathrm{A}$ \\
\hline$\# 5$ & 100 & $\mathrm{CB}+\mathrm{HP}$ & $4 \mathrm{HP}$ & & $7 ; 4 ; \mathrm{A}++$ & $5 ; 4 ; \mathrm{A}$ & $5 ; 4 ; \mathrm{A}$ \\
\hline$\# 6$ & 65 & $\mathrm{CB}$ & $3 \mathrm{HP}$ & & $7 ; 6 ; \mathrm{A}$ & $12 ; 3.5 ; \mathrm{A}$ & $7 ; 0.5 ; \mathrm{B}$ \\
\hline$\# 7$ & 65 & $\mathrm{NCB}$ & $1 \mathrm{HP}$ & & $7 ; 5 ; \mathrm{A}+$ & $6 ; 7 ; \mathrm{A}$ & \\
\hline$\# 8$ & 60 & $\mathrm{CB}$ & & & $7 ; 2 ; \mathrm{A}++$ & $12 ; 1.5 ; \mathrm{A}+$ & \\
\hline$\# 9$ & 95 & NCB & $2 \mathrm{HP}$ & & $7 ; 5 ; \mathrm{A}+++$ & $12 ; 8 ; \mathrm{A}+$ & \\
\hline
\end{tabular}


Table A5. Cont.

\begin{tabular}{|c|c|c|c|c|c|c|c|}
\hline Archetype & Floor Surface $\left[\mathrm{m}^{2}\right]$ & Heating and DHW* & Cooling * & PV Array & $\mathbf{W M} * *$ & $\mathrm{DW} * *$ & $\mathrm{TD} * *$ \\
\hline$\# 10$ & 102 & $\mathrm{NCB}$ & $1 \mathrm{HP}$ & & $7 ; 3 ; \mathrm{A}+$ & $14 ; 5 ; \mathrm{A}$ & \\
\hline$\# 11$ & 67 & $\mathrm{CB}$ & & & $10 ; 5 ; \mathrm{B}$ & $6 ; 5 ; \mathrm{B}$ & \\
\hline$\# 12$ & 134 & $\mathrm{CB}$ & & & $7 ; 6 ; \mathrm{A}$ & $14 ; 7 ; \mathrm{A}$ & $6 ; 3 ; \mathrm{B}$ \\
\hline$\# 13$ & 124 & $\mathrm{CB}$ & & & $5 ; 4 ; \mathrm{A}$ & $12 ; 7 ; \mathrm{A}+$ & \\
\hline$\# 14$ & 123 & $\mathrm{NCB}+$ solar collectors & & $3.9 \mathrm{~kW}$ & $5 ; 4 ; \mathrm{A}$ & $12 ; 7 ; \mathrm{A}+$ & \\
\hline
\end{tabular}

* NCB: Non-Condensing Boiler; CB: Condensing Boiler; HP: Heat Pump; ${ }^{* *}$ WM: Washing machine; DW: Dishwasher; TD: Tumble dryer; Capacity, cycles per week, Energy Class.

Table A6. Family composition of each archetype.

\begin{tabular}{ccc}
\hline Archetype & Occupants ${ }^{*}$ & Description \\
\hline$\# 1$ & $4 ;(1 ; 3 ; 4 ; 4)$ & Family with two teenage children and one unemployed parent \\
\hline$\# 2$ & $2 ;(0 ; 0 ; 2 ; 2)$ & Commuter Workers \\
\hline$\# 3$ & $4 ;(0 ; 3 ; 4 ; 4)$ & Family with school-aged children, and one part-time working parent \\
\hline$\# 5$ & $1 ;(0 ; 0 ; 1 ; 1)$ & Commuter Worker \\
\hline$\# 6$ & $4 ;(1 ; 3 ; 4 ; 4)$ & Family with school-aged children, and one home parent \\
\hline$\# 7$ & $4 ;(1 ; 3 ; 4 ; 4)$ & Family with school-aged children and babies, and one unemployed parent \\
\hline$\# 8$ & $3 ;(0 ; 0 ; 3 ; 3)$ & Commuter worker, awaiting employment \\
\hline$\# 10$ & $2 ;(1 ; 1 ; 2 ; 2)$ & Family with a school-aged child, and one commuter worker \\
\hline$\# 11$ & $3 ;(1 ; 2 ; 3 ; 3)$ & Family of commuter workers \\
\hline$\# 12$ & $2 ;(0 ; 1 ; 2 ; 2)$ & Family with a school-aged child, and two commuter workers \\
\hline$\# 13$ & $3 ;(0 ; 2 ; 3 ; 3)$ & Family with two adult children, two commuter parents \\
\hline$\# 14$ & $4 ;(0 ; 1 ; 4 ; 4)$ & Family with a school-aged child, and two commuter workers \\
\hline $2 ;(0 ; 1 ; 2 ; 2)$ & Two Pensioners \\
\hline $2(2 ; 2 ; 2 ; 2)$ &
\end{tabular}

* Number of occupants; (8 a.m. to 1 p.m.; 1 p.m. to 7 p.m.; 7 p.m. to 12 a.m.; 12 a.m. to 8 a.m.).

\section{References}

1. European Commission. A Clean Planet for All A European Strategic Long-Term Vision for a Prosperous, Modern, Competitive and Climate Neutral Economy; European Commission: Brussels, Belgium, 2018.

2. Brouwer, A.S.; Van Den Broek, M.; Seebregts, A.; Faaij, A. Impacts of large-scale Intermittent Renewable Energy Sources on electricity systems, and how these can be modeled. Renew. Sustain. Energy Rev. 2014, 33, 443-466. [CrossRef]

3. Schibuola, L.; Scarpa, M.; Tambani, C. Demand response management by means of heat pumps controlled via real time pricing. Energy Build. 2015, 90, 15-28. [CrossRef]

4. Haider, H.T.; See, O.H.; Elmenreich, W. A review of residential demand response of smart grid. Renew. Sustain. Energy Rev. 2016, 59, 166-178. [CrossRef]

5. Magnago, F.H.; Alemany, J.; Lin, J. Impact of demand response resources on unit commitment and dispatch in a day-ahead electricity market. Int. J. Electr. Power Energy Syst. 2015, 68, 142-149. [CrossRef]

6. Eurostat Statistics I Eurostat/. Available online: https:/ / ec.europa.eu/eurostat/databrowser/view/ten00124/default/table? lang=en (accessed on 31 March 2020).

7. Foteinaki, K.; Li, R.; Heller, A.; Rode, C. Heating system energy flexibility of low-energy residential buildings. Energy Build. 2018, 180, 95-108. [CrossRef]

8. Jensen, S.Ø.; Marszal-Pomianowska, A.; Lollini, R.; Pasut, W.; Knotzer, A.; Engelmann, P.; Stafford, A.; Reynders, G. IEA EBC Annex 67 Energy Flexible Buildings. Energy Build. 2017, 155, 25-34. [CrossRef]

9. Rahmani-Andebili, M. Scheduling deferrable appliances and energy resources of a smart home applying multi-time scale stochastic model predictive control. Sustain. Cities Soc. 2017, 32, 338-347. [CrossRef]

10. Chen, Y.; Xu, P.; Gu, J.; Schmidt, F.; Li, W. Measures to improve energy demand flexibility in buildings for demand response (DR): A review. Energy Build. 2018, 177, 125-139. [CrossRef] 
11. Cumo, F.; Curreli, F.R.; Pennacchia, E.; Piras, G.; Roversi, R. Enhancing the urban quality of life: A case study of a coastal city in the metropolitan area of Rome. WIT Trans. Built Environ. 2017, 170, 127-137. [CrossRef]

12. Péan, T.; Costa-Castelló, R.; Salom, J. Price and carbon-based energy flexibility of residential heating and cooling loads using model predictive control. Sustain. Cities Soc. 2019, 50, 101579. [CrossRef]

13. De Santoli, L.; Lo Basso, G.; Astiaso Garcia, D.; Piras, G.; Spiridigliozzi, G. Dynamic Simulation Model of Trans-Critical Carbon Dioxide Heat Pump Application for Boosting Low Temperature Distribution Networks in Dwellings. Energies 2019, 12, 484. [CrossRef]

14. Mazzoni, S.; Ooi, S.; Nastasi, B.; Romagnoli, A. Energy storage technologies as techno-economic parameters for master-planning and optimal dispatch in smart multi energy systems. Appl. Energy 2019, 254, 113682. [CrossRef]

15. Nastasi, B. Hydrogen policy, market, and R \& D projects. In Solar Hydrogen Production: Processes, Systems and Technologies; Elsevier: Amsterdam, The Netherlands, 2019; pp. 31-44. ISBN 9780128148549.

16. Nastasi, B.; Lo Basso, G.; Astiaso Garcia, D.; Cumo, F.; de Santoli, L. Power-to-gas leverage effect on power-to-heat application for urban renewable thermal energy systems. Int. J. Hydrogen Energy 2018, 43, 23076-23090. [CrossRef]

17. Roversi, R.; Cumo, F.; D'Angelo, A.; Pennacchia, E.; Piras, G. Feasibility of municipal waste reuse for building envelopes for near zero-energy buildings. WIT Trans. Ecol. Environ. 2017, 224, 115-125. [CrossRef]

18. D'Ettorre, F.; De Rosa, M.; Conti, P.; Testi, D.; Finn, D. Mapping the energy flexibility potential of single buildings equipped with optimally-controlled heat pump, gas boilers and thermal storage. Sustain. Cities Soc. 2019, 50. [CrossRef]

19. Mancini, F.; Romano, S.; Lo Basso, G.; Cimaglia, J.; De Santoli, L. How the italian residential sector could contribute to load flexibility in demand response activities: A methodology for residential clustering and developing a flexibility strategy. Energies 2020, 13, 3359. [CrossRef]

20. Lucas, A.; Jansen, L.; Andreadou, N.; Kotsakis, E.; Masera, M. Load Flexibility Forecast for DR Using Non-Intrusive Load Monitoring in the Residential Sector. Energies 2019, 12, 2725. [CrossRef]

21. Mancini, F.; Lo Basso, G.; De Santoli, L. Energy Use in Residential Buildings: Characterisation for Identifying Flexible Loads by Means of a Questionnaire Survey. Energies 2019, 12, 2055. [CrossRef]

22. Siano, P.; Sarno, D. Assessing the benefits of residential demand response in a real time distribution energy market. Appl. Energy 2016, 161, 533-551. [CrossRef]

23. Agbonaye, O.; Keatley, P.; Huang, Y.; Bani-mustafa, M.; Hewitt, N. Design, Valuation and Comparison of Demand Response Strategies for Congestion Management. Energies 2020, 13, 6085. [CrossRef]

24. Rashid, M.M.U.; Granelli, F.; Hossain, M.A.; Alam, M.S.; Al-Ismail, F.S.; Karmaker, A.K.; Rahaman, M.M. Development of Home Energy Management Scheme for a Smart Grid Community. Energies 2020, 13, 4288. [CrossRef]

25. Yao, L.; Hashim, F.H.; Lai, C.-C. Dynamic Residential Energy Management for Real-Time Pricing. Energies $2020,13,2562$. [CrossRef]

26. Mancini, F.; Basso, G.L.; Santoli, L.D. Energy use in residential buildings: Impact of building automation control systems on energy performance and flexibility. Energies 2019, 12, 2896. [CrossRef]

27. Afzalan, M.; Jazizadeh, F. Residential loads flexibility potential for demand response using energy consumption patterns and user segments. Appl. Energy 2019, 254, 113693. [CrossRef]

28. D’hulst, R.; Labeeuw, W.; Beusen, B.; Claessens, S.; Deconinck, G.; Vanthournout, K. Demand response flexibility and flexibility potential of residential smart appliances: Experiences from large pilot test in Belgium. Appl. Energy 2015, 155, 79-90. [CrossRef]

29. Finck, C.; Li, R.; Zeiler, W. Optimal control of demand flexibility under real-time pricing for heating systems in buildings: A real-life demonstration. Appl. Energy 2020, 263, 114671. [CrossRef]

30. Feuerriegel, S.; Neumann, D. Integration scenarios of Demand Response into electricity markets: Load shifting, financial savings and policy implications. Energy Policy 2016, 96, 231-240. [CrossRef]

31. Shirazi, E.; Jadid, S. Cost reduction and peak shaving through domestic load shifting and DERs. Energy 2017, 124, 146-159. [CrossRef]

32. Zheng, M.; Meinrenken, C.J.; Lackner, K.S. Smart households: Dispatch strategies and economic analysis of distributed energy storage for residential peak shaving. Appl. Energy 2015, 147, 246-257. [CrossRef] 